\title{
An evaluation of Ontario-based website accessibility - A comparison with US findings.
}

\author{
by
}

\author{
Gavin Kelly
}

A thesis submitted to the Faculty of Graduate and Postdoctoral Affairs in partial fulfillment of the requirements for the degree of

\author{
Master of Arts \\ in \\ Political Science
}

Carleton University

Ottawa, Ontario

(C) 2017, Gavin Kelly 


\begin{abstract}
Website accessibility is becoming more important for persons with disabilities. Over 1 in 6 people worldwide, have some form of disability. (World Health Organization, 2016) Access to websites is seen as a fundamental aspect of a modern information society recognized by the United Nation Convention on the Rights of People with Disabilities (United Nations, 2006). Web accessibility studies aim to identify, discuss and ultimately reduce limitations for persons with disabilities. Despite decades of advocacy and a wealth of guidelines, testing studies suggest that most websites are still not accessible. This study evaluated and compared the accessibility of 50 of the most important websites in Ontario with those in the Baltimore area. Findings showed that the Ontario websites were less accessible than those in the Baltimore area study, despite longer exposure to the same accessibility rules. This suggests that there may be other factors that determine a website's level of accessibility. This paper discusses these potential explanations such as legislation, guidelines, implementation, awareness, and incentives for web developers.
\end{abstract}




\section{Acknowledgements}

I would like to acknowledge Dr. Conrad Winn for his irreplaceable contributions to this work to help persons with disabilities. I would like to thank Dr. Scott Bennett for intrepidly taking up my cause and providing me with his usual fearless advice. I would like to thank my fiancée Lara Sun for convincing me to take on this Masters in Political Science. Finally, I would like to acknowledge Marysia Laverriere for making the world a better place. 


\section{Table of Contents}

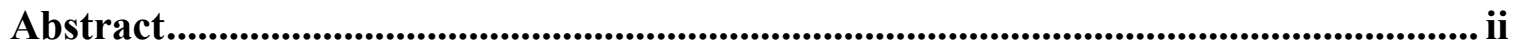

Acknowledgements ......................................................................................................ii

Table of Contents ............................................................................................................ iv

List of Figures and Tables...................................................................................... vii

List of Appendices................................................................................................................. viii

1 Chapter: Introduction ....................................................................................................... 1

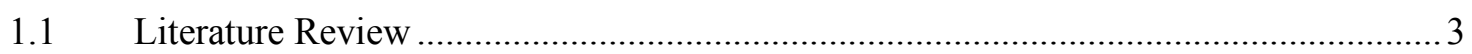

1.1.1 Approach to Literature Review .........................................................................

1.1.2 Website Accessibility Literature ………………………………………………….

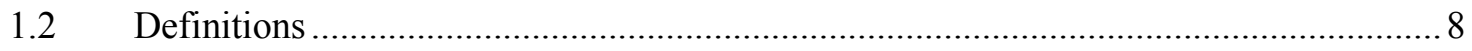

1.2.1 Accessibility ..................................................................................

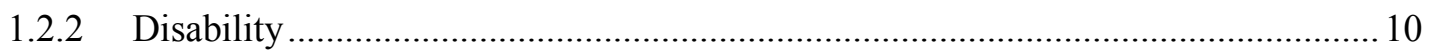

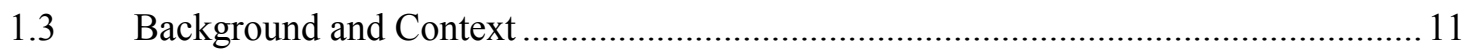

1.3.1 Canadian Disability Policy and Law .................................................................... 11

1.3.2 Foundations of Website Accessibility laws in Canada ........................................... 12

1.3.3 Standards for Website Accessibility ......................................................................... 13

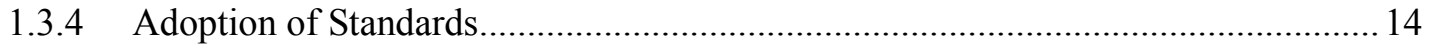

2 Chapter: Research ....................................................................................................... 15

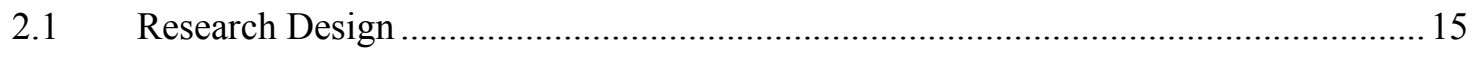

2.1.1 Methods for Evaluating Website Accessibility …………………………………..... 15

2.1.2 Comparison Study - High Level Principles ................................................................ 16

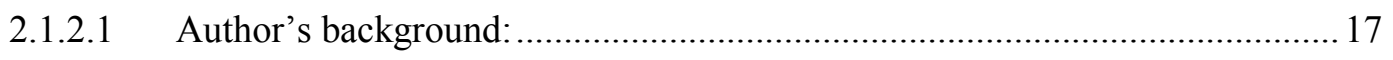

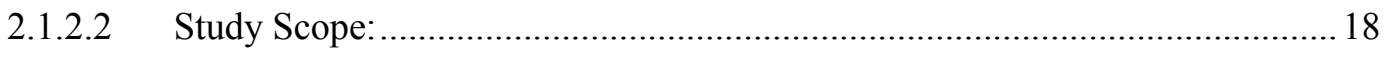

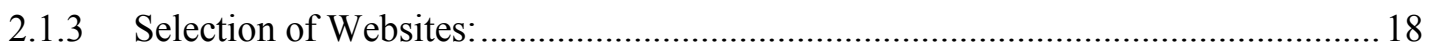




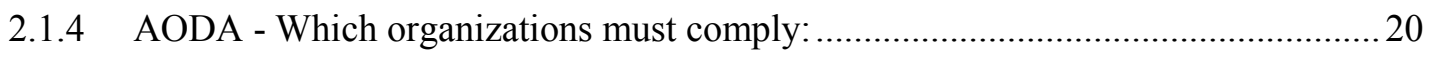

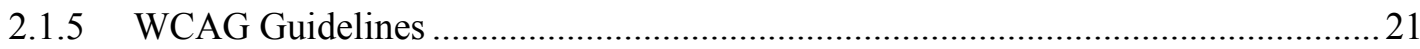

2.1.6 Reconciling differences between WCAG guidelines 1.0 and 2.0 ..........................2

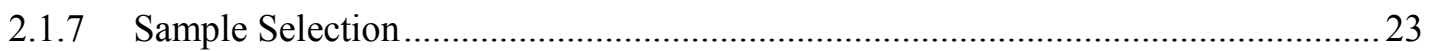

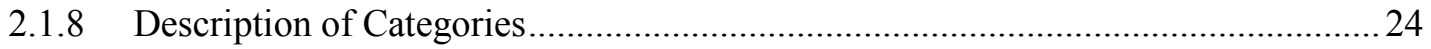

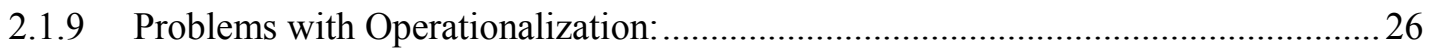

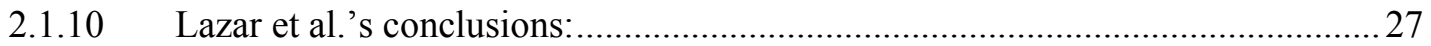

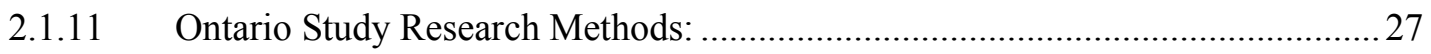

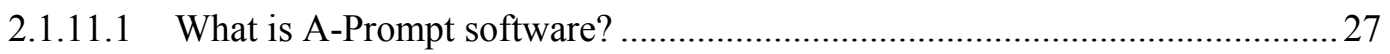

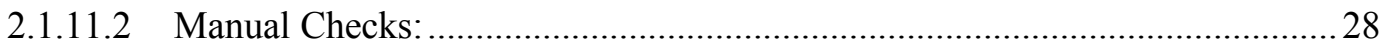

2.1.11.3 WCAG Priority Level One Violations not tested by A-Prompt software: .......28

2.1.11.4 Determining a Homepage's Levels of Accessibility ......................................29

2.1.11.5 Evaluating Homepage Accessibility ................................................................22

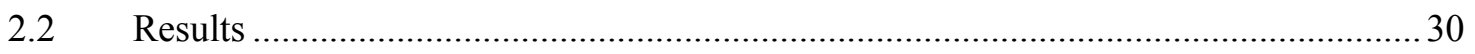

2.2.1 Number of Ontario Websites in each of Lazar et al.'s Accessibility Levels.............31

2.2.2 Number of Ontario Homepages that violated each WCAG Priority one guideline .32

2.2.3 Average number of violations per website category in Ontario.............................. 32

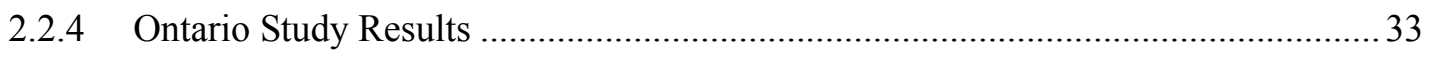

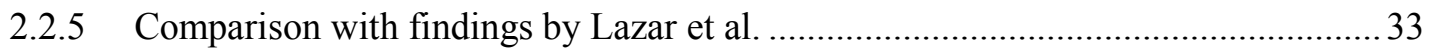

2.2.6 Comparison: Websites in each of Lazar et al.'s accessibility level.......................... 34

2.2.7 Comparison: Number of Homepages that violated each WCAG priority one

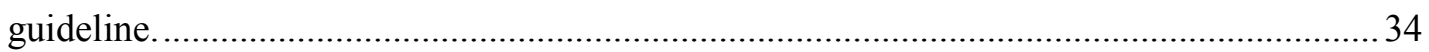

2.2.8 Comparison: Average number of violations per organization category.................... 36

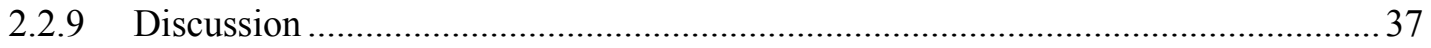

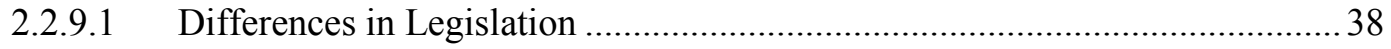

2.2.9.2 WCAGs represented in United States Section 508 .......................................... 39 


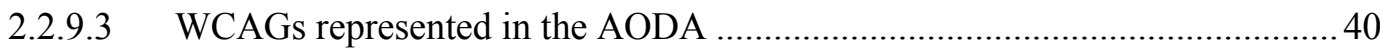

2.2.9.4 Differences in amount of time exposed to WCAG....................................... 41

2.2.10 Factors Related to Website Accessibility - Secondary research questions .......... 41

2.2.10.1 Are the findings of the Ontario study consistent with other research on website

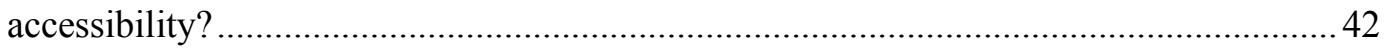

2.2.11 Are government and web developer websites more accessible than the average? 45

2.2.12 Comparison between urban and rural library website accessibility .....................46

2.2.13 Are French websites more or less accessibility than English websites? ..............48

2.2.14 Is there a significant difference in Web Accessibility between Federal, Provincial

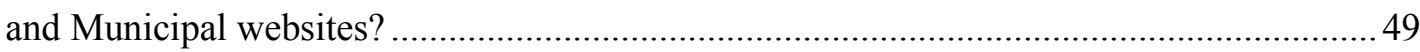

2.2.15 How do changes in technology impact the evaluation of Ontario websites?.......49

2.2.16 What is the impact of WCAG violation 6.3. (Requirement for Javascript)? .......50

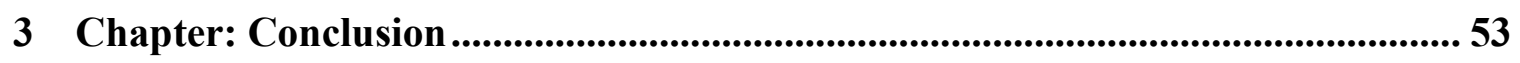

3.1 Conclusions on the Secondary Research Questions: .............................................53 


\section{List of Figures and Tables}

Figure 1 - Burke's Falls Library image - November 22nd 2017 ........................................ 47

Figure 2 - Ontario.ca Image When Javascript is Disabled.............................................. 52

Table 1 - Number of organizations in each category ..................................................... 19

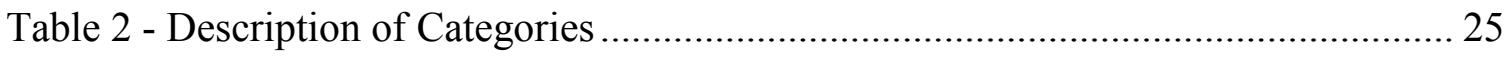

Table 3 - Accessibility level of rules violated …………................................................ 29

Table 4 - Ontario Websites per Accessibility Level ........................................................ 31

Table 5 - Quick Reference WCAG Priority Level 1....................................................... 31

Table 6 - Number of Violations per WCAG.................................................................. 32

Table 7 - Avg. Violations per Organization Category …………………………….......... 32

Table 8 - Comparison of Websites in each of Lazar et al.'s Accessibility Levels ........... 34

Table 9 -Lazar et al. Number of Homepages which violated WCAG Guidelines............. 35

Table 10 -Degree of Difference between Ontario and Baltimore Study Findings ............ 36

Table 11 - Comparison: Categories vs Avg. Number of Violations.................................... 36

Table 12 - Comparison: Average number of Violations................................................... 37

Table 13 - Correlation between "image missing alternative text " and "link to accessibility

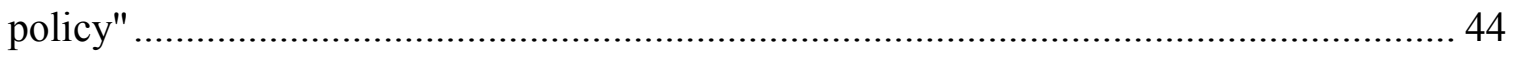

Table 14 - Correlation between, "headers not identified in data tables" and "link to

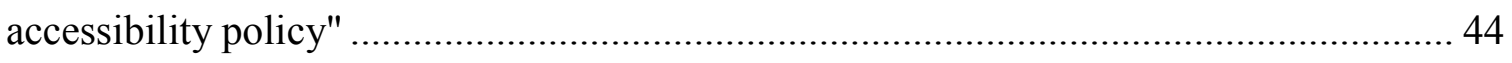

Table 15 - Specific Categories vs. the Average Number of Violations ............................ 46

Table 16 - Comparison of Rural and Urban Library Homepages..................................... 47

Table 17- Comparison of Federal, Provincial and Municipal Homepages........................ 49 


\section{List of Appendices}

Appendices Error! Bookmark not defined.

Appendix A - Research and Search Methodology .............Error! Bookmark not defined. Appendix B - Web Content Accessibility Guidelines (WCAG) Priority Level One Error! Bookmark not defined. Appendix C - Lazar et al.'s Guide to Manual Website Checks for WCAG Priority Level One Guidelines .............................................................Error! Bookmark not defined. Appendix D - United States Accessibility Board: WCAG 2.0 Guidelines and Section 508 differences:...........................................................Error! Bookmark not defined. Appendix E - Thompson et al. Accessibility Ratings by Presence of Accessibility policy....................................................................................Error! Bookmark not defined. Appendix F - Sample of Ontario Websites .........................Error! Bookmark not defined. 


\section{Chapter: Introduction}

According to studies conducted in the U.S and U.K., website accessibility rates remain low despite decades of exposure to website accessibility guidelines. With website accessibility legislation in Ontario being in place for years, are websites in the province consistent with this trend? If legislation and guidelines have existed in Ontario since 2005, (Accessibility for Ontarians with Disabilities Act, 2005) what are the factors that influence low rates of accessibility amongst Ontario websites? And, how does website accessibility in Ontario compare with that of states in the U.S? This study will review previous evaluations of website accessibility in academic literature. Through a deconstruction of Ontario's accessibility laws and policies, this study will explore potential causes of low website accessibility rates and analyze the principles of accessibility policy. From this foundation, the results of a 2003 study of accessibility levels for websites in the Baltimore-area will be compared to Ontario-based websites. Significant attention will be paid to the websites of Governments and web developers, as these groups have a more direct influence on the accessibility and design of websites in general.

The central research question for this paper is whether Ontario-based websites are more or less accessible than those in the Baltimore-area and if so why? It will be demonstrated that, websites in Ontario have a lower level of accessibility than those in the Baltimore-area despite a difference of 16 years between studies. This suggests that the amount of time a jurisdiction has been exposed to accessibility rules does not sufficiently explain their website's level of accessibility. Other factors need to be considered when proposing approaches to make websites more accessible. Secondary 
research questions will be used to explore features of Ontario web accessibility and potential factors related to the lower rate of accessibility.

In the course of conducting research and searching for factors related to the above conclusion, the following secondary research questions were developed:

1. Are the findings of the Ontario study consistent with other research on website accessibility?

2. Are government and web developer websites more accessible than the average?

3. Are rural libraries less accessible than urban libraries?

4. Are French website more or less accessibility than English websites?

5. Is there a significant difference in Web Accessibility between Federal, Provincial and Municipal websites?

6. How do changes in technology impact the evaluation of Ontario websites?

7. What is the impact of WCAG violation 6.3. (Requirement for Javascript)? These questions will guide the discussion on website accessibility and contribute to potential pathways to future research. In order for this research to make a contribution with strong validity, a triangulation approach to research will be used. This involves using qualitative and quantitative methods to investigate elements of the central research question. This research also intends to make a significant contribution to accessibility literature by being a first-of-its-kind evaluation of website accessibility in Ontario. 


\subsection{Literature Review}

\subsubsection{Approach to Literature Review}

A review of web accessibility literature was conducted using several methods to sufficiently contextualize this study within existing research. The review was part focused review and part full review. (See Appendix A: Research and Search methodology for more details) For the concept of disability a full review was conducted. For the literature on website accessibility only relevant and recent findings were researched. The purpose of this approach was to narrow overall concepts and then provide a sufficiently deep exploration of the variables and the potential relationship between them. The above thesis statement would be impossible to prove based on past research alone, so it was necessary to conduct original research. Overall the aim is not to bridge the gap between fields but to take on a focused review of website accessibility literature. This review establishes the state of web accessibility research and begins to explore several potential frameworks for understanding website accessibility rates.

\subsubsection{Website Accessibility Literature}

Over 1 in 6 people worldwide, have some form of disability. (World Health Organization, 2016) This includes visual, cognitive, auditory and motor impairments. These impairments can cause limitations when accessing websites. For example, being hard of hearing, deaf, or blind, has an effect on how users interface and experience websites. (W3C Web Accessibility Initiative, 2005) Furthermore, accessibility is seen as

a fundamental aspect of the modern information and knowledge society that is recognized by the United Nation Convention on the Rights of People with Disabilities (United Nations, 2006). Web accessibility studies aim to identify, discuss and ultimately reduce 
limitations for persons with disabilities. At least one study in the U.S. has formally examined the relationship between accessibility and rates of internet use. Fox concluded that poor implementation of accessibility guidelines may contribute to low rates of internet use among Americans with disabilities. (Fox, 2011) To further underscore the underscore this issues current relevance, the World Health Organization expects the ratio of disabilities worldwide to increase to due to aging populations. (World Health Organization, 2016)

Despite decades of advocacy and a wealth of guidelines, testing tool studies suggest that most websites are still not fully accessible. (Zeng, 2005) In Canada and the U.S., accessibility standards for websites exist but do not seem to guarantee accessibility. In a study of 100 U.S. government home pages, Olalere found that over $90 \%$ of the pages tested had accessibility errors that violated U.S accessibility laws. (Olalere, 2011) Thompson found that most websites for educational organizations in the Colorado area did not meet accessibility standards. (Thompson T. , 2009) Foundational work by Lazar et al. from 2004 indicated that over 70\% of websites in the Baltimore area were inaccessible according to the Web Content Accessibility Guidelines (WCAG) version 1.0 standards. (Lazar J. D.-S., 2004) While this research is not generalizable to all areas and sectors, this demonstrates that in many cases websites are not complying with web accessibility guidelines.

Several studies address the perception that complying with web accessibility guidelines actually makes websites less accessible to non-disabled users. In testing of this premise, Schmutz found that websites which follow WCAG 2.0 have benefits for disabled users as well as non-disabled users. (Sven Schmutz, 2017) Ellcessor et al. took 
on different facets of the web design industries', "disability myths-list." (Ellcessor, 2014) For example, it is commonly claimed that making a website more accessible will also make it un-attractive, boring, or dull. It is also suggested that changing a website to meet accessibility guidelines may alienate some users or result in lost income. (Ellcessor, 2014) Contrary to this claim, Lazar et al. suggest that applying accessibility standards to websites would open these site up to more users who would otherwise be unable to access them. (Lazar J. B.-D., 2003) Comparative research from 2017 suggests that websites which followed web accessibility guidelines are just as accessible, and in some cases more accessible, for non-disabled users. (Sauer, 2017) While there no consensus on the effects on non-disabled users, most research suggests that web accessibility guidelines have the potential to provide benefits and reduce barriers for people with disabilities. Towards the goal of reducing barriers for people with disabilities, several studies explore potential factors that are related to a websites' level of accessibility. Research into low website accessibility levels can be divided into two groups. Studies that explores factors external to websites and those that explore factors internal to websites.

Regarding factors external to websites, several governments have undertaken studies to identify issues with the implementation of website accessibility guidelines. In the United Kingdom, a 2004 investigation by the Disability Rights Commission found that only $29 \%$ of Small to Medium Enterprises took accessibility "into account" while building a website. Their follow-up survey indicated that $69 \%$ were, "aware of accessibility as an issue”. Large organizations were more aware of accessibility at $97 \%$, however only $68 \%$ of these considered accessibility during the building of a website. (Disability Rights Commission., 2004) More recent studies indicated that more 
education about accessibility is needed for developers Freire et al. found that $45 \%$ web developer were aware of screen readers for blind users but this group of developers also indicated that they did not know how to make web pages compatible with screen readers. (Freire et al., 2008) These external factors are often not taken into account in research exploring relationships between internal website features and levels of accessibility

Regarding internal factors, there is a lack of academic consensus on whether there is a relationship between a website's features and its level of accessibility. In Gibertson and Machin's study, they analyze low levels of website accessibility as a two-sided problem. On the one hand, website developers may not be integrating accessibility principles into their website designs. On the other hand, clients of web developers are not requesting accessible designs. When it comes to the former, Gilbertson and Machin notice that many web developers falsely claim that their websites are in conformance with accessibility standards. In their study, Gilbertson and Machin conducted an evaluation of the homepages of 100 web development companies. Among other findings, they discovered that references to accessibility on a developer's homepage had no relationship to the page's overall level of accessibility. (Gilbertson, 2012) Furthermore they concluded that even if the website advertised accessibility with the presence of validation and conformance icons, that there was no correlation to that website being more accessible.

Contrary to this finding, research by Thompson et al. challenges the premise that a reference to an accessibility policy is not related to a website's level of accessibility. In a study of U.S. colleges, Thompson et al. found that predictors of web accessibility might include an institution's, "policies, procedures, and support strategies.” (Thompson T. B., 
2003) In their follow-up study ten years later, they identified specific factors related to web accessibility. Their study measured a website's level of accessibility in relation to references of web accessibility standards or policies. The method for determining a website's level of accessibility was through a semi-automated web search for references to accessibility policies at each institution. They found that conformance with certain web accessibility guidelines was a strong predictor of whether or not that site referenced an accessibility policy. The primary focus of their research was not to rank the accessibility of websites but search for relationships between variables related to web accessibility. To their research question, "Which independent variables are the best predictors of web and PDF accessibility?" (Thompson T. C., 2013) they indicted that, "the inclusion of alt text with images and labeled input fields," (Thompson T. C., 2013) were the strongest predictors of variance in having an, "accessibility link on their home page." (Thompson T. C., 2013) To help close the research gap between Thompson and, Gilbertson and Machin, the specific premise above will be tested later under this study's research question, as to whether the findings of the Ontario study are consistent with other research on website accessibility. Testing this premise should also help to develop a stronger consensus within web accessibility research.

The majority of web accessibility research has been conducted in the U.S. In searching for past academic evaluations of Ontario websites, none were found. Major studies by Vigo, Arrue, Brajnik, and Lomuscio in Vancouver 2007 are the closest comparators for what this study hoped to achieve. Many of these studies suggest that a more unified approach is needed to advance the field of web accessibility research. (Zeng, 2005) (Vigo, 2007) Towards unifying website accessibility research, this study 
proposes to build upon existing definitions and methods in order to achieve more comparable and generalizable results.

\subsection{Definitions}

\subsubsection{Accessibility}

The W3C Web Accessibility Initiative (W3C), which established the WCAG, note that the definition of accessibility can sometimes be barrier to access. (W3C Web Accessibility Initiative, 2005) Across, academia, governments and other organizations, a common understanding of accessibility is required to improve outcomes related to the accessibility of websites. Accessibility can be defined as the property of a website such that people with some impairment can use it with the same effectiveness as non-disabled people. (Slatin, 2003) While Slatin's definition refers explicitly to websites, the concept of accessibility is applicable to many other types of devices that allow access to the internet. The concept of use in this definition speaks to the types of physical disability that research seeks to address. For example, there is little research on intellectual, or predispositional barriers to accessing websites. Seale outlines two essential assumptions inherent in the broad term accessibility. Accessibility is used to describe both access to any technology and access in any environment or location. (Seale, 2006) The concept of Website accessibility addresses two more specific interactions, the user interface and the human component, which involves the perception, interpretation and interaction with said user interface. The user interface side of website accessibility concerns itself with human ability and the related definition of disability. Numerous academic articles focus on defining disability theoretically, practically and legally. This can be problematic for determining the best way to study web accessibility because there is, "no commonly 
accepted definition of developmental disability.” (Rosenau, 2010) Rosenau identifies three categories of disability definitions in literature. These subgroups are, "intellectual disability, developmental disability, and special health care needs (which include chronic physical, developmental, behavior, and emotional conditions.)" (Rosenau, 2010) Rosenau suggests that definitions in literature tend to favour the case they are studying. For the purposes of this paper I explored the definition of disability as explained in the Accessibility for Ontarian's with Disabilities Act (AODA). That is, "a physical or mental condition that limits a person's movements, senses, or activities." (Accessibility for Ontarians with Disabilities Act, 2005) The source for the AODA's definition of disability is the Ontario Human Rights Code. This definition of disability is suitably broad as opposed to exhaustive for exploring the many potential factors related to low levels of website accessibility.

Utilizing comparable approaches to studying web accessibility helps to advance research in this field. There is significant literature on the needs and challenges that disabled populations face in North America. However, information on the sources of these challenges is not comprehensive. Theories on causal explanations of web accessibility barriers for disabled populations, “are not unified," (Rosenau, 2010) and methods for studying these problems are not standardized. So while issues often have similarities, research into potential relationships between these issues is rarely comparable. Furthermore, any structural analysis of institutions, policies and services that are designed to address these issues is not easily found in academic literature. For the Ottawa and Ontario areas, many reports but few academic studies exist from the past 10 
years. One advantage of conducting comparative research is that it may help to contribute a more consistent narrative across the field of disability literature.

\subsubsection{Disability}

Theories on disability often begin by addressing social expectations about how the majority of a population interacts with the environment. (Rosenau, 2010) Just as Rosenau suggests, most literature uses a definition of disability relative to its context. In Ontario, the Accessibility for Ontarians with Disabilities Act defines a disability as a physical or mental condition that limits a person's movements, senses, or activities. (Accessibility for Ontarians with Disabilities Act, 2005) Most Canadian definitions of disabilities originate from the World Health Organization's (WHO) definition. (Brajnik, Testability and validity of WCAG 2.0: the expertise effect. , 2010) In the WHO's definition, disability in children and adults are measured against ability norms. An example of an ability norms would be that an 18 year old person should be able to walk and be able to read words on a page. When a person fails to meet these standards they are defined as having a disability, or a delay. Some disabilities have a clearly identifiable physiological element. For example, cerebral palsy is bleeding in the brain before or soon after birth that has damaged the nervous system. Others, such as Autism Spectrum Disorder, are diagnosed by a failure to meet several developmental milestones that are considered specific to this disorder. Assessing the needs of the disabled population in policy and practice is then a complicated task for public servants, executives and website designers. 
Some authors suggest that the approach to defining disability in academic research does not match the approach of standards-keeping organizations. Lewthwaite explains some limitations to the literary definition of disability and the problem this causes for standards-keeping organizations. She states that, "currently, dominant web accessibility standards do not respect disability as a complex and culturally contingent interaction." (Lewthwaite, 2011) Instead, most academic research recognizes the variable of disability as a, "contrary and political power relation, rather than a biological limit." (Lewthwaite, 2011) Research that revisits the definition of disability in web accessibility then has the potential to broaden the scope of its applications to include standardskeeping organizations. Lewthwaite states succinctly that, "Web accessibility standards are designed to enact universal principles, however, they express partial and biopolitical understandings of the relation between disability and technology.” (Lewthwaite, 2011) Improved reconciliation between academic researcher and standards-keeping bodies would help with the practical objective of improving website accessibility.

\subsection{Background and Context}

\subsubsection{Canadian Disability Policy and Law}

Rights for persons with disabilities are enshrined in several documents throughout the federal, provincial and territorial governments of Canada. At the provincial level the Ontarians with Disabilities Act, 2001 outlines the laws and rules for bodies that service persons with disabilities. At the Federal level, the Canadian Human Rights Act 1977 protects Canadians from discrimination from employers and when they receive certain services. This act specifically identifies several physical and mental disabilities. The Canadian Charter of Rights and Freedoms forms the first part of the Constitution Act, 
1982. Section 15 (1) and (2) of the Charter guarantees the equal protection and equal benefit of the law to all, with a specific mention of mental and physical disability. This section undoubtedly helped to shape accessibility laws in Canada as it is used as the foundation in several disability discrimination cases that reached the Supreme Court of Canada.

\subsubsection{Foundations of Website Accessibility laws in Canada}

A significant degree of disability law in Canada has been shaped by court cases. The website for the Accessibility for Ontarians with Disabilities Act cites the Jodhan vs the Attorney General of Canada case as being foundational to the design of Ontario's legislation. (Accessibility for Ontarians with Disabilities Act, 2005) In this case, Donna Jodhan, who was a visually impaired special-needs consultant, launched a lawsuit against the federal government when she encountered a series of barriers when applying to a job on the government's website. (Canada, 2012) In 2010, a Federal Court ruled that, "inaccessible federal government websites violated the right to equality which section 15 of the Canadian Charter of Rights and Freedoms guarantees to all persons with disabilities in Canada." (Canada, 2012) 2012) In a surprise move, the federal government appealed the decision which led to a constitutional challenge. The appeal found in favor of Jodhan and the federal government was ordered to grant visually impaired people equal access to the services and information on all federal government websites.

In their decision, the judge also found that there was, "evidence of a systematic problem," of website accessibility in the Canadian government. (Canada, 2012) The ruling required the Canadian government to update its standards to meet the WCAG version 2.0. 


\subsubsection{Standards for Website Accessibility}

For researchers and practitioners, the Web Content Accessibility Guidelines 2.0 (WCAG 2.0) are the most commonly accepted standards for assessing whether or not a website is accessible for persons with a disability. (Sven Schmutz, 2017) Several jurisdictions have enshrined these guidelines into their legal standards, including Ontario's AODA. In the U.S., there are several other prominent sources of web accessibility guidelines. These include, the World Wide Web Consortium's Web Accessibility Initiative (WAI) www.w3.org/WAI) The U.S. National Cancer Institute's Research-based Web Design \& Usability Guidelines (www.usability.gov/guidelines ) the Universal Usability Guide (universalusability.org/index.html), and the IBM Ease of Use Web Design Guidelines (www3.ibm.com/ibm/easy/eou ext.nsf/Publish/572Printview). The U.S. government's legal requirements for website accessibility are commonly referred to as the Section 508 guidelines. Section 508 of the Rehabilitation Act of 1973 requires federal agencies and their contractors to make websites accessible to employees and members of the public. The Department of Justice is currently developing accessibility rules for non-governments sites under the Americans with Disabilities Act from 1990. (Program, Accessed July 2017)

Internationally, the WCAG 2.0 guidelines have been adopted as the foundation for disability legislation in several countries. Namely the U.S., U.K., Canada, and Australia. In the European Union (EU), the European Council adopted Resolution 7087/02 regarding accessibility of public web sites and their content. This resolution calls for the non-mandatory adoption of website accessibility standards by all EU Member 
states. In the United Kingdom, web accessibility is required under the 2010 Equality Act, and conformance is determined through the web accessibility standard BS 8878: 2010. In Australia, conformance with WCAG 2.0 is required of all government websites. In Canada, the federal Standard on Web Accessibility from 2011 sets requirements for government website based on WCAG 2.0 guidelines. These requirements are the foundation of Ontario's AODA and their web accessibility policies.

\subsubsection{Adoption of Standards}

Despite widely agreed upon standards, studies confirm that many governments struggle with adoption and implementation of website accessibility. (Velleman, 2015) Although adoption usually takes place at high-levels of governments, the task of implementation often falls to local levels of government. A top-level to bottom-level study of government implementation in the EU found that, while commitments have contributed to more awareness among stakeholders, the actual implementation of accessibility standards is still behind the target set by EU adoption. (European Union, 2012) In one study, the most significant barrier to adoption was identified as the perceived complexity of the WCAG guidelines. (Velleman, 2015) The second most significant barrier was identified as a lack of resources and technical capability. Top-level government adoption may involve the establishment of tools to allow lower levels of government to implement required changes.

Secondary to their research, Velleman et al. asked the question, which factors within municipalities influence the process of adoption and implementation of accessibility standards for websites? They note that, while adoption is an important first step, research should consider the real-world effects that policy has on individuals and 
groups. For this reason, this study seeks to evaluate the results of adoption and implementation of web accessibility guidelines and also conduct research. In their research, Velleman et al. use semi-structured interviews with disability legislation stakeholders to gauge the impact of web accessibility guidelines. These methods would be useful to follow-up on findings from this study. The method for evaluating whether Ontario-based websites are more or less accessible than those in the Baltimore-area, will be explained in the next section.

\section{Chapter: Research}

\subsection{Research Design}

\subsubsection{Methods for Evaluating Website Accessibility}

This study seeks to answer the above research question by undertaking a comparison study and following previously established methods used in a study by Lazar et al. This section will explain what method of analysis was used and why. As noted in Lazar et al.'s study, obtaining a full understanding of a website's accessibility requires electronic and manual evaluation. While web accessibility tools are able to identify certain WCAG violations with relative consistency, the identification of some violation still require human judgment. Electronic evaluation has the advantage of being a more repeatable and consistent method of evaluation, allowing for an easier comparison between studies to be made. A study by Brajnik et al. investigated the effectiveness of human evaluation of WCAG 2.0 alone. This study compared the accuracy of findings from both expert and non-expert evaluators. Each group of evaluators were asked to find all of the WCAG 2.0 violations on four different web pages. Brajnik et al. found that 
WCAG 2.0 conformance cannot be accurately tested by human inspection to a level where $80 \%$ of expert human evaluators would agree on the conclusion. (Brajnik, Testability and validity of WCAG 2.0: the expertise effect. , 2010) For researching website accessibility they note that electronic evaluation tools help remove ambiguity from evaluations.

\subsubsection{Comparison Study - High Level Principles}

This study replicated the method used in Lazar et al.'s website accessibility study in order to generate comparable results. Replication of methodology has several advantages for research, including contributing to a more consistent narrative across the field of web accessibility literature. Replication studies involve repeating a study from an academic journal using the same methods but with different subjects. This involves taking the conclusion of a previous study and applying it to new situations. The goal of this approach is to expand on the body of website accessibility research that exists and make a contribution that has a uniquely Canadian (Ontario) context. This should create parallel narratives that overall strengthen the dialogue around website accessibility. At the same time, this research will be testing the generalizability of Lazar, et. al's conclusions. The following high-level principles were followed for this comparison study.

This study will:

- Assess the validity of the previous studies results;

- Assess the relationships of variables as they are explained in the baseline study;

- Test Lazar et al.'s conclusion; 
- Apply the research method and results to an Ontario-based study; and

- Continue the narrative and discussion around website accessibility and encourage new research.

After searching through various journals the methods to evaluated website accessibility, work by Lazar et al. was chosen, titled: Web accessibility in the Mid-Atlantic United States: a study of 50 homepages, from 2003. (Lazar J. B.-D., 2003) The following section will examine features of this comparison study.

\subsubsection{Author's background:}

The authors of this study have a rich history of disability advocacy. Research into author's backgrounds is intended to explicitly identify any potential bias that may have influenced their intentions for undertaking this research. This study was co-authored by Jonathan Lazar, Yogesh Nagpappa, Patricia Beere and Kisha-Dawn Greenridge. Jonathan Lazar has been a Professor of Computer and Information Sciences at Towson University since 1999. He has been involved in several disability advocacy organizations and also acted as a consultant for the U.S. federal government for issues related to website accessibility. (University of Towson, 2017) The other authors all worked for the Center for Applied Information Technology at Towson University, however other reliable information on their background proved difficult to find. Regarding potential motivations for this study, Lazar, et al. claim that website accessibility provides overall benefits for all persons, not just those with disabilities. Their study does not address potential negative effects of compliance with website accessibility guidelines. The authors cite lawsuits against America Online, South-West Airlines, and the 2000 Sydney Olympics as creating the imperative for their study. (Lazar J. B.-D., 2003) 


\subsubsection{Study Scope:}

Lazar et al.'s study evaluates websites based on the Wide Web Consortium Web Accessibility Initiative's Web Content Accessibility Guidelines (WCAG) and the United States federal government's Section 508 guidelines. In the U.S., all federal websites were expected comply with Section 508 by 2001. Lazar et al.'s study took place 2 years after these regulations took effect. The authors chose to test website's homepages with the rational that homepages are the gateway to other sections of the website. If users encounter accessibility problems on the homepage then they may have difficulty accessing other sections of the website. This study of Ontario websites will also focus on the evaluation of homepages.

\subsubsection{Selection of Websites:}

Lazar et al.'s study was built upon work by Sullivan and Matson, who sought to evaluate the 50 most used websites in the world for their accessibility. (Lazar J. B.-D., 2003) (Sullican, 2000) Lazar et al. claimed that they wanted to study the effect that exposure to legislation would have on web accessibility, specifically the effect that Section 508 guidelines would have in the Baltimore area. As the Ontario study is trying to develop a picture of disability issues in a specific region, the Lazar et al. study is a better model than the Sullivan study for comparison. Lazar et al.'s stated goal was to study the websites of the most important organizations in the Mid-Atlantic area, and those that people were most likely to use. They collected a list of websites from two publications, the Baltimore Business Journal's Book of Lists (2002) and the Baltimore Sun. From these lists they selected a sample of websites for their study by filtering through several principles. Their study selected websites according to: 
1) The most important, companies, organizations and government agencies in the region;

2) The largest publicly traded companies in the region;

3) Organizations that fit into only one of their ten major categories; and

4) Maintaining a relatively even distribution of websites throughout their categories. (Shown below)

\begin{tabular}{|l|c|}
\hline \multicolumn{1}{|c|}{ Category } & Target \# of Organizations \\
\hline Colleges and Universities & 6 \\
\hline Non-Profit Organizations & 4 \\
\hline State/Local Government Organizations & 7 \\
\hline Information Technology Firms & 5 \\
\hline Manufacturing Firms & 5 \\
\hline Private Firms & 7 \\
\hline Sports and Recreation & 2 \\
\hline Web Development/Web Design Firms & 4 \\
\hline Health/Disability Organizations & 6 \\
\hline Software Development Firms & 4 \\
\hline
\end{tabular}

Table 1 - Number of organizations in each category

Though measures such as, "most important website," are subjective, this study does provide a reasonable foundation for creating a comparative study. According to the methods section, the aforementioned lists were cross-referenced to identify 120 of the largest and most important companies, organizations, and government agencies in the region.

As with Lazar et al.'s study, rankings from prominent publications were used to create a list of organizations for this study's sample. Publications from The Globe and Mail, Clutch, Topseos, Macleans and Arch Disability Law were used to populate a list of organizations with head offices located in Ontario upon which to draw from. The scope of this study was limited to the geographical jurisdiction of Ontario, however the intended audience for websites is not geographically restricted. Websites may be 
designed to interact with people all over the world, not just those in Ontario. Further, there is a contrast between the Lazar et al. study and this study in the jurisdictional definition. While the Lazar et al. study focused on a general area around Baltimore, this study will be focused on the Canadian province of Ontario. This is done to simplify research into a jurisdiction that has uniform laws (AODA) governing website accessibility. As mentioned earlier, the top organizations in Canada may not have localized bases in Ontario, and only organizations that have head offices in Ontario are subject to AODA regulations. (Accessibility for Ontarians with Disabilities Act, 2005) As a result this study chose to focus on organizations with head offices in Ontario.

\subsubsection{AODA - Which organizations must comply:}

As of January 1, 2014 all organizations in Ontario with 50 or more employees that create new internet websites and web content on those sites must conform with WCAG 2.0 Level A (also known as priority one guidelines). By January 1, 2021, all internet websites and web content must conform with WCAG 2.0 Level AA (priority level two guidelines), other than several audio-criteria guidelines. By 2021 all organizations in Ontario will be expected to have websites that are compliant with the AODA regulations. (Accessibility for Ontarians with Disabilities Act, 2005) According to the AODA regulations, any organization located in Ontario that has one or more employee(s) and that also has other offices outside Ontario is required to comply with the AODA. The requirement for an office to be located in Ontario leads to several interesting exceptions to accessibility rules. Where a website may not be required to be accessible because its head office is not located in Ontario (or Canada) and its website was developed outside of Canada (for non-Canadian users) but it operates a business inside Ontario. This would 
mean that several businesses that are being scrutinized are not subject to the AODA and yet these websites still effects the population in Ontario. Having a location-based requirement for rules around internets services highlights the difficulties for regional regulators.

\subsubsection{WCAG Guidelines}

The WCAG 1.0 were published in 1999 by the World Wide Web Consortium and the WCAG 2.0 were published in November of 2008. (W3C Web Accessibility Initiative, 2005) The U.S. was the first country to incorporate these guidelines into legislation by including these standards in the Americans with Disabilities Act (Termens, 2009) Canada was among the other countries that incorporated these standards into its legislation, by including these standards in the AODA in 2005. By the time of the Ontario study, the World Wide Web Consortium had updated its guidelines from version 1 to 2 .

\subsubsection{Reconciling differences between WCAG guidelines 1.0 and 2.0}

Despite differences in timing, the comparison between both studies is still relevant as it is possible to directly correlate WCAG 1 and 2. This study and Lazar et al.'s study from 2003 measured website accessibility using WCAG guidelines 1.0. In 2008 the World Wide Web consortium updated its guidelines to WCAG 2.0. The 2.0 guidelines represent the consortium's current standard for web accessibility and are also directly referenced in Ontario's AODA. This change begs the questions, are evaluations of Ontario websites based on WCAG 1.0 relevant now that WCAG 2.0 has come into effect?

It is relevant for this study to test Ontario websites using the WCAG 1.0 as the standard for the following reasons: 1) WCAG 1.0 are guidelines that are accepted by 
many countries and groups worldwide and represent a standard that is widely agreed upon by policy experts, web developers and disability advocates. 2) Testing using the same standard allows for a comparison of web accessibility between Ontario and U.S. websites (that use WCAG 1.0 standards in the Section 508 guidelines). 3) Testing the same guidelines over several years allows for some inferences about the progression of web accessibility over time. 4) Research that addresses the comparability of WCAG 1.0 and 2.0 finds a direct correlation from 1 to 2 . As will be discussed later, this makes it possible to understand the level of accessibility for a website developed under WCAG 2.0 in the context of the WCAG 1.0 guidelines.

Despite these reasons, there exists several challenges to the validity of the methods used to operationalize this study. In particular, Since WCAG 2.0 guidelines have come into effect, Ontario websites may be striving to meet those standards and not the WCAG 1.0. Further, web development practices have likely changed since the WCAG standards were first introduced. This means that testing modern websites on previous standards may limit the relevance of advice for future web-developers and policy-makers. Ultimately the distance between WCAG 1.0 and 2.0 represents the limit for what conclusions this study can explain regarding the accessibility of Ontario websites in the modern context.

Research by Termens et al. helps to reconcile the changes in WCAG 1.0 and 2.0. For the purposes of this study, their most significant conclusion is that, the former WCAG 1.0 criteria were retained as relevant categories in WCAG 2.0. (Termens, 2009) They find that WCAG 2.0 is published with a great deal of supplementary documentation that make it far more educational, less ambiguous and more testable than WCAG 1.0. 
(Termens, 2009) They recognize the WCAG 1.0 as being aligned with four broader principles of testing. That is, a guideline much be, Perceivable, Operable, Understandable and Robust. Termens et al. note that the WCAG 2.0 attempt to correct many of the WCAG 1.0 testability flaws. In WCAG 1.0 many guidelines were so ambiguous that functionally deficient websites were able to comply with the letter of the accessibility standards whilst infringing its spirit. (Termens, 2009) This lack of specificity was listed by Termens et al. as a potential explanation for slow progress in making real-world change on website accessibility. In the Lazar et al. study and in the discussion section of this study, several WCAG 1.0 guidelines were disqualified for testing because they are too ambiguous for meaningful evaluation. Termens et al. also provide an image that demonstrates how WCAG 1.0 guidelines map to the WCAG 2.0 guidelines. (Attached in Appendix D) This map shows how it would be possible to evaluate a website's level of accessibility against WCAG 2.0 based on its WCAG 1.0 scores. Their analysis provides some certainty that the WCAG 1.0 guidelines used in the Lazar et al. study and in this study are still a relevant measure of website accessibility.

\subsubsection{Sample Selection}

This study followed Lazar et al.'s methodology when assembling a list of organizations from Canadian publications. From these lists a sample was selected using Lazar et al's four above-noted principles (Page 19). Overall this sample represents a profile of the most significant organizations in Ontario that fit into each of Lazar et al.'s categories. All of these organizations were required to have an office with an address in Ontario, as they are then subject to the AODA. Beside the above principles, organizations were selected based on those that were listed at the top in number of employees in 
Ontario and revenue. According to research conducted by the Oxford Internet Institute, the websites for the federal Government of Canada $\left(14^{\text {th }}\right)$ and TD Canada Trust $\left(21^{\text {st }}\right)$ are in the top 25 most accessed sites in Canada. (Canadian Broadcasting Corporation, 2013) Amazon.com's Alexa web monitoring service ranks TD Canada Trust $\left(19^{\text {th }}\right)$ Royal Bank of Canada, $\left(20^{\text {th }}\right)$ the Canadian Broadcasting Corporation, $\left(24^{\text {th }}\right)$ and the University of Toronto $\left(48^{\text {th }}\right)$ among the 50 most accessed websites in Canada in 2017. (Amazon Alexa, 2017) (See Appendix F for the full Sample of Ontario Websites)

\subsubsection{Description of Categories}

Lazar et al. did not include an explanation of how they created categories in the original study. The only directional statement regarding their organizing of websites by category was that they intended to have an, "even distribution of websites into each category," while also capturing the, "largest and most commonly used websites in the Baltimore area." (Lazar J. B.-D., 2003) They relied on magazines other publications for determining which websites were considered the largest and most commonly used. In compiling their sample, they found that some categories had many websites while some had few. To balance this, websites with overlapping missions and roles were, "randomly removed," (Lazar J. B.-D., 2003) so that the remaining sites provided a more broad analysis of the area. Although somewhat subjective, the same considerations were used in compiling a sample of websites for this study. For additional clarity I have provided the following broad descriptions and parameters for the categories in this study. 


\begin{tabular}{|c|c|}
\hline Category & Description \\
\hline Colleges and Universities & $\begin{array}{l}\text { Colleges and Universities recognized through one of Universities } \\
\text { Canada's accreditation programs. }\end{array}$ \\
\hline Non-Profit Organizations & $\begin{array}{l}\text { Organizations that are have tax-exempt or charity status in } \\
\text { Ontario. }\end{array}$ \\
\hline $\begin{array}{l}\text { State and local Government } \\
\text { Organizations }\end{array}$ & $\begin{array}{l}\text { In the Lazar et al. study this category was used to capture websites } \\
\text { run by the State of Maryland or jurisdictions within. }\end{array}$ \\
\hline -became- & This study operationalized their concept of "Government \\
\hline Municipal, Provincial, Federal & \\
\hline Organizations & $\begin{array}{l}\text { Canadian jurisdictions exist, the use of Federal, Provincial and } \\
\text { Municipal websites should capture the concept of Government } \\
\text { Organizations and make for a more interesting comparison. The } \\
\text { evaluation of Canadian governmental websites is also important as } \\
\text { these are bodies responsible for developing accessibility rules in } \\
\text { Canada. }\end{array}$ \\
\hline Information Technology Firms & $\begin{array}{l}\text { Information technology firms are those companies that play a } \\
\text { significant role in media, telecom, internet or communications } \\
\text { industries. }\end{array}$ \\
\hline Manufacturing Firms & $\begin{array}{l}\text { Manufacturing firms include any company that uses components } \\
\text { or raw materials to make a finished good. }\end{array}$ \\
\hline Private Firms & $\begin{array}{l}\text { Firms include any for-profit incorporation. This category is not } \\
\text { exclusive to any particular firms. In Lazar et al.'s study, } \\
\text { companies in this category seem to be chosen to represent sectors } \\
\text { of society that had the largest and most frequently used websites } \\
\text { that were not captured by the other categories. For example, in the } \\
\text { Ontario study, Loblaws Companies was listed by the Globe and } \\
\text { Mail as the largest employer in Ontario and as such was included } \\
\text { in this category. }\end{array}$ \\
\hline Sports and Recreation & $\begin{array}{l}\text { This category includes firms whose primary business activities } \\
\text { include sporting events. }\end{array}$ \\
\hline $\begin{array}{l}\text { Web Development/Web } \\
\text { Design Firms }\end{array}$ & $\begin{array}{l}\text { A web development firm includes those whose main business } \\
\text { activities are writing markup and coding. Web design firms main } \\
\text { business activities are the ascetic components of websites. }\end{array}$ \\
\hline $\begin{array}{l}\text { Health/ } \\
\text { Disability Organizations }\end{array}$ & $\begin{array}{l}\text { Health and Disability organizations include government } \\
\text { organizations, non-profits and for-profit firms. Websites in this } \\
\text { category provide health-related services or information. }\end{array}$ \\
\hline Software Development Firms & $\begin{array}{l}\text { Software development firms are those firms whose main business } \\
\text { activity is the creation and maintenance of programs or other } \\
\text { information used by computers. }\end{array}$ \\
\hline
\end{tabular}

Table 2 - Description of Categories 


\subsubsection{Problems with Operationalization:}

Research in social science uses concepts as tools to simplify, understand and study real world phenomenon. Some predictability can be added to social science models through data analysis. In data analysis, measures of validity help researchers to understand the limitations of survey questions as they relate to reality. Put another way, measures of validity establish what a research method is capable of proving and what it is not. The central research question for this paper is, whether Ontario-based websites are more or less accessible than those in the Baltimore-area and if so why? One limitation of using electronic evaluation software as the primary method to address the central question is a lack of analysis of Ontario websites over time. This studies' method provides snapshot of a potential current state of compliance but cannot contextualize whether this is improving or declining. According to Hull et al. research on website accessibility should include a measure of performance over time, as a common feature of disability is, "inconsistency of ability over time." (Ian M. Hull, 2004) This is further explained by Mossa. While a person with a developmental disability may be able to provide for their needs most days, "elevated health risks, seizures, emotional instability, and impairment issues can limit their ability." (Mossa., 2015) This means that while a population's needs are being met at the moment, this will likely change over time. For the findings of this study, any conclusions will be at best a snapshot of the problem rather than a reliable and contextualized artifact. 


\subsubsection{Lazar et al.'s conclusions:}

Lazar et al.'s study examined the accessibility of 50 homepages across the MidAtlantic United States (Baltimore area). Their central research question was to determine what accessibility problems exists for those homepages. Their study found that 49 out of 50 Web sites had accessibility violations, according to both the WCAG priority level 1 and the U.S. Government's Section 508. They also concluded that with some modifications, most of these sites could be made completely accessible. This study proposed to see if the websites in Ontario have a similar level of inaccessibility. Furthermore the results of this study were compared with Lazar et al.'s to examine differences and speculate as to potential causes.

\subsubsection{Ontario Study Research Methods:}

\subsubsection{What is A-Prompt software?}

This study uses the same web accessibility tool as Lazar et al. called A-Prompt. Web accessibility tools are software that are designed to help web authors improve the accessibility of websites. A-Prompt is a free software made available through a collaboration between the Adaptive Technology Resource Centre at the University of Toronto and the TRACE Center at the University of Wisconsin. These research centers are dedicated to improving the accessibility and usability of information technologies by people with disabilities. (University of Toronto, 2012) A-Prompt first evaluates HTML web pages to identify barriers to accessibility for people with disabilities then provides a report with recommended fixes. The tool's evaluation and repair checklist is based on WCAG 1.0 accessibility guidelines created and maintained by the Web Accessibility Initiative of the World Wide Web Consortium. A-Prompt's website claims that, while 
this tool was designed to address the challenges faced by persons with disabilities, improving accessibility can also widen the range of users who can access a website. For example, including text alternatives for all images allows people with low-bandwidth internet or less powerful devices to access content. While A-Prompt is able to identify many levels of violations, both Lazar et al. and this study are primarily examining WCAG 1.0 priority level one violations.

\subsubsection{Manual Checks:}

Several violations detected by A-Prompt involve a degree of subjectivity and therefore require manual checks. The software's accompanying guide indicates that these manual checks are reported as, "possibly causing an accessibility problem.” (University of Toronto, 2012) Manual checks in the Ontario study were performed by following Lazar et al.'s methodology to ensure consistent evaluation. The section of Lazar et al.'s study that addresses Manual Check is referenced in Appendix C. These guidelines also cover the U.S. Section 508 guidelines, as one of the components of Lazar et al.'s study included comparing these guidelines with the WCAG 1.0. An examples of a violation that requires manual checks would be 2.1 , whether colour is used as the only distinguishing feature of content on a website.

\subsubsection{WCAG Priority Level One Violations not tested by A-Prompt software:}

WCAG priority level one guidelines $1.3,11.4$, and 14.1 are not tested by APrompt. As discussed by Lazar et al. these violations are not easily categorized as, "yes" or "no" but are intended as guidelines for web-developers. In this way they cannot be 
tested by the software's check of homepage HTML, nor can they be checked through a subjective manual review.

\subsubsection{Determining a Homepage's Levels of Accessibility}

The homepages of 50 organizations from Ontario were examined to determine their level of accessibility. The results of this study were compared to the findings from Lazar et al.'s study of U.S. webpages in the Baltimore area. For each homepage it was noted how many WCAG 1.0 priority level one guidelines were violated. These homepages were then rated according to their level of accessibility based on Lazar et al.'s scoring system. This study has applied several additional levels of analysis that Lazar et al. did not in order to explore potential causes of inaccessibility. This evaluation should provide valuable information on homepage accessibility to web developers, policymakers and website users.

\subsubsection{Evaluating Homepage Accessibility}

Lazar et al. evaluated a homepage's level accessibility based on the number of WCAG priority one rules it violated. They did not rate websites based on the total number of violations. Their stated rational was that, "from a practical point of view, for those who are trying to update a Web site to make it accessible, different guideline

\begin{tabular}{ll}
\hline $\begin{array}{l}\text { Category } \\
\text { (\# of Violations) }\end{array}$ & $\begin{array}{l}\text { Accessibility } \\
\text { Level }\end{array}$ \\
\hline 0 rules violated: & Accessible \\
\hline 1 to 3 rules violated: & $\begin{array}{l}\text { Marginally } \\
\text { inaccessible }\end{array}$ \\
4 to 6 rules violated: & $\begin{array}{l}\text { Moderately } \\
\text { inaccessible } \\
\text { Substantially } \\
\text { inaccessible }\end{array}$ \\
\hline
\end{tabular}

Table 3 - Accessibility level of rules violated violations are more challenging to fix rather than numerous instances of the same guideline violation.” (Lazar J. B.-D., 2003) They reason that it would be easier to fix 10 
instances of an image that was missing alternative text, than 1 instance of 10 different WCAG violations. From the user point of view, dealing with 10 different types WCAG violations means making 10 different adjustments in order to access the content of a website. This study retained this framework but also built upon it to create a more comprehensive analysis that will be discussed later. See Table 3 to view the scale that was used to apply general labels of accessibility to websites. Lazar et al's categories label a website according an increasing degree of difficulty in both accessing a site and addressing its violations. The authors explain that the guidelines were not weighted because different guidelines address different disabilities, and therefore determining which guideline is more important is equivalent to determining which disability is more important. (Lazar J. B.-D., 2003)

\subsection{Results}

The results of this study show that websites in Ontario have an overall lower level of accessibility than homepages in the Baltimore-area studied by Lazar et al. in 2003. The following section will first focus on this study's overall findings in Ontario. Later sections will discuss secondary research questions and analyzes these results for potential future investigations. In the final section, these results will be compared with Lazar et al. to explore the uncovered differences. The findings of this study were organized into the following three categories:

1. Number of Ontario websites in each of Lazar et al.'s accessibility levels;

2. Number of Ontario homepages that violated each WCAG Priority one guideline; and

3. Average number of violations per website category in Ontario. 


\subsubsection{Number of Ontario Websites in each of Lazar et al.'s Accessibility Levels}

The majority of website

homepages evaluated in

Ontario were rated to be,

"Marginally inaccessible."

With most violating between 1-

3 WCAG priority level one

rules. The following tables and

\begin{tabular}{|c|c|c|}
\hline $\begin{array}{l}\# \text { of } \\
\text { Ontario } \\
\text { websites }\end{array}$ & $\begin{array}{l}\text { Category } \\
\text { (\# of Violations) }\end{array}$ & $\begin{array}{l}\text { Accessibility } \\
\text { Level }\end{array}$ \\
\hline $\mathbf{0}$ & 0 rules violated: & Accessible \\
\hline 33 & $\begin{array}{l}1 \text { to } 3 \text { rules } \\
\text { violated: }\end{array}$ & $\begin{array}{l}\text { Marginally } \\
\text { inaccessible }\end{array}$ \\
\hline 16 & $\begin{array}{l}4 \text { to } 6 \text { rules } \\
\text { violated: }\end{array}$ & $\begin{array}{l}\text { Moderately } \\
\text { inaccessible }\end{array}$ \\
\hline 1 & $7+$ rules violated: & $\begin{array}{l}\text { Substantially } \\
\text { inaccessible }\end{array}$ \\
\hline
\end{tabular}

Table 4 - Ontario Websites per Accessibility Level

figures show the results of data collection and analysis. Table 4 shows how many Ontario websites were scored into each of Lazar et al.'s accessibility levels. A quick-reference description for each WCAG priority level one guidelines is provided in the table below. Further description of each WCAG priority level one guideline is can be found in Appendix B.

\begin{tabular}{|c|l|}
\hline $\begin{array}{c}\text { WCAG level } \\
\text { one priority }\end{array}$ & \\
\hline 1.1 & Image missing text alternative \\
\hline 1.2 & Provide redundant text links for active server-side image maps \\
\hline 1.4 & Video/audio missing descriptive text \\
\hline 2.1 & Hyperlinks only identified by colour / underline \\
\hline 4.1 & Language changes not indicated \\
\hline 5.1 & Headers not identified in data tables \\
\hline 5.2 & Data table not identified \\
\hline 6.1 & Style sheets missing image texts \\
\hline 6.2 & Equivalents for dynamic content is provided when dynamic content is updated \\
\hline 6.3 & Website SCRIPT is missing \\
\hline 7.1 & Flickering occurs \\
\hline 9.1 & Image maps provided \\
\hline 12.1 & Title each frame for identification and navigation. \\
\hline
\end{tabular}

Table 5 - Quick Reference WCAG Priority Level 1 


\subsubsection{Number of Ontario Homepages that violated each WCAG Priority one guideline}

The most commonly violated WCAG 1.0 Priority level one guidelines was: 1.1 Providing a text equivalent for non-text graphics. 49 out of 50 homepages were flagged by A-Prompt for this violation. (See Table 6 below)

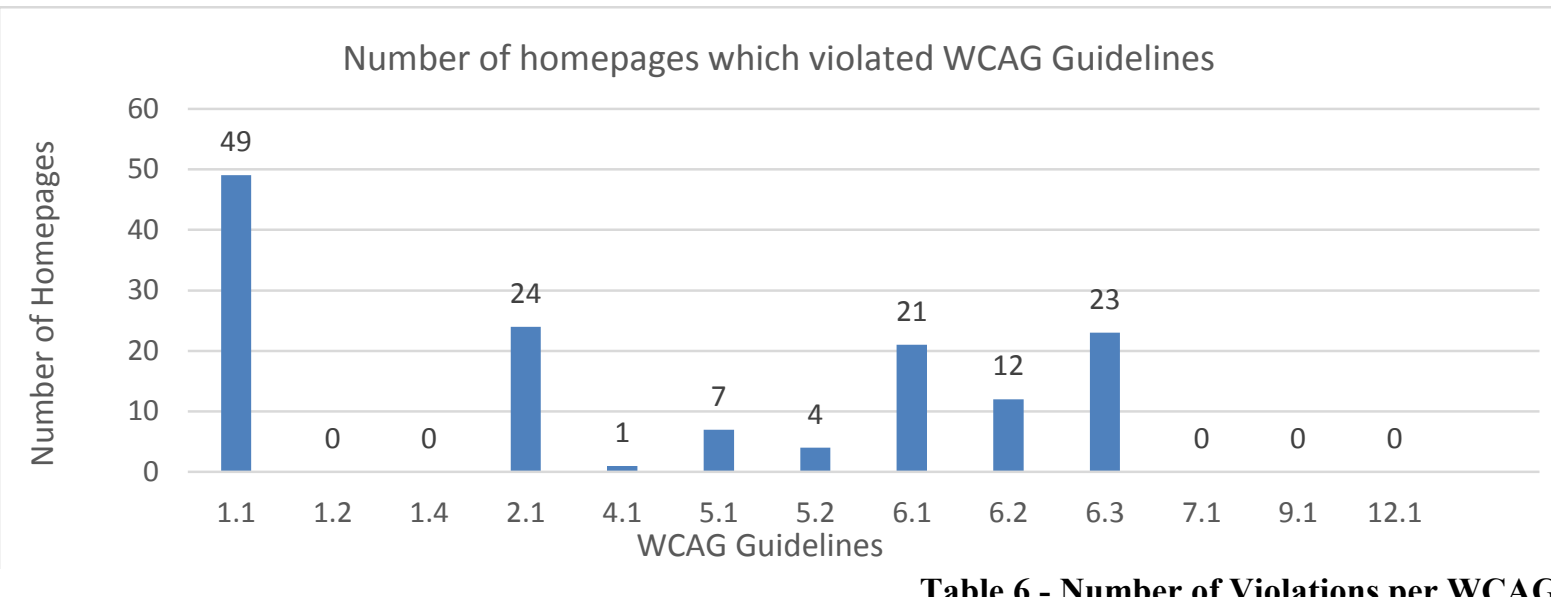

\subsubsection{Average number of violations per website category in Ontario.}

Table 7 below displays the average number of accessibility violations per website category for the WCAG priority level one guidelines. The average number of violations is on the y-axis, and the ten different categories are on the $\mathrm{x}$-axis.

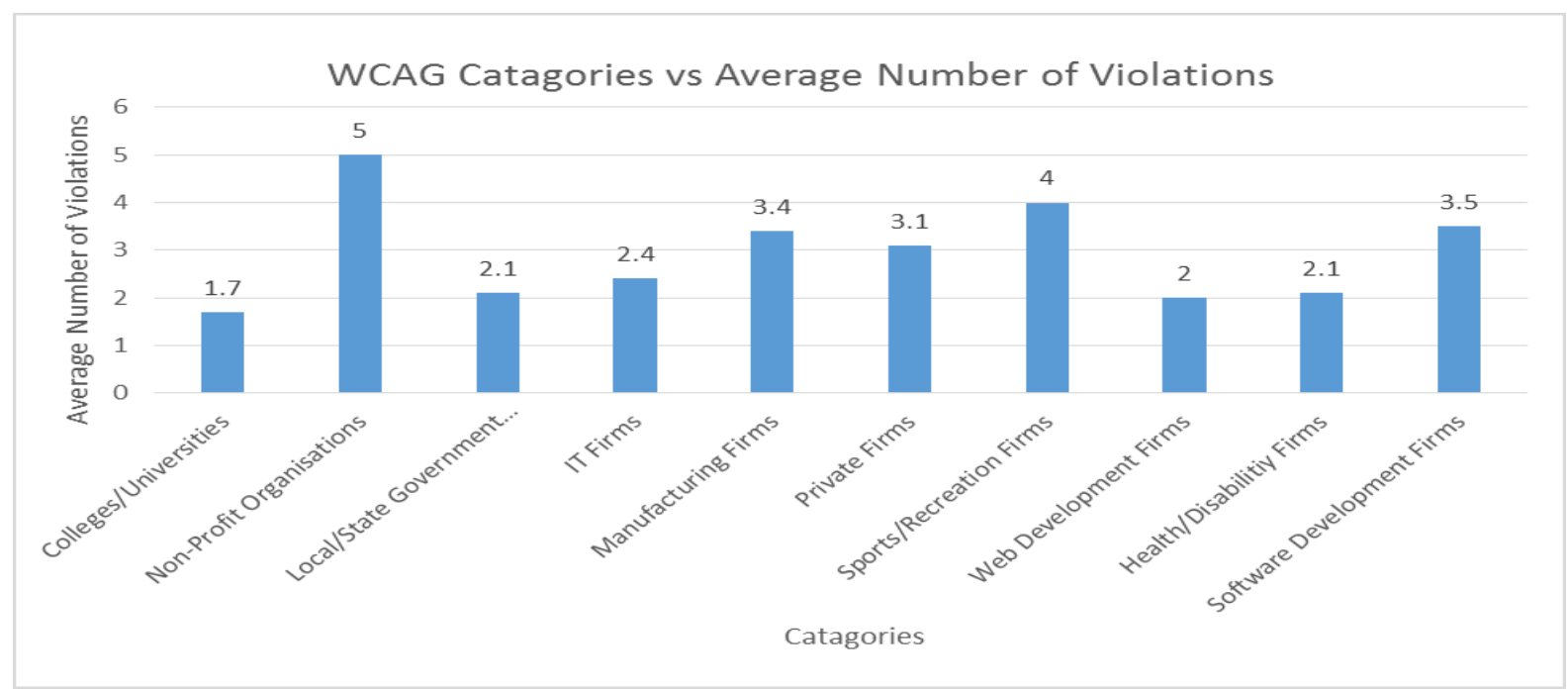

Table 7 - Avg. Violations per Organization Category 
The category with the highest number of average violations according to WCAG priority level one is Non-profit organizations, with an average of 5 priority level one violations. The category with the lowest number of average violations is Colleges and Universities, with 1.7 .

\subsubsection{Ontario Study Results}

12 years after the introduction of AODA rules that establish WCAG guidelines as mandatory for all websites in Ontario, none of the 50 sites evaluated was accessible according to WCAG priority level 1 guidelines. That 34\% (17 out of 50) of websites were moderately inaccessible or worse indicates that issues which first prompted the introduction of this legislation have not been completely addressed. A more in-depth analysis of these findings and a comparison with Lazar et al.'s study provide some insight into potential causes of these issues.

\subsubsection{Comparison with findings by Lazar et al.}

The findings of the Ontario study were compared with the findings of the Baltimore-area study by Lazar et al. The comparison showed that on average Ontario websites are less accessible and have more accessibility violations than those in the Baltimore-area study. The following section is a side-by-side comparison between the findings of these studies. Later sections will discusses the comparison's relevance to the overall body of web accessibility literature and also relate findings to secondary research questions. By following the same research methodology as Lazar et al., this analysis provide a foundation exploring differences between these two jurisdictions and potential explanations of different levels of website accessibility. 


\subsubsection{Comparison: Websites in each of Lazar et al.'s accessibility level}

The Ontario study found more homepages to be moderately and substantially inaccessible than those in the Baltimore area. Table 8 compares the number of Ontario websites in each of Lazar et al.'s accessibility levels with the study of Baltimore-area websites.

\begin{tabular}{ccll}
\hline $\begin{array}{c}\text { \# of Ontario } \\
\text { websites }\end{array}$ & $\begin{array}{l}\text { \# of Baltimore- } \\
\text { area websites }\end{array}$ & $\begin{array}{l}\text { Category } \\
\text { (\# of Violations) }\end{array}$ & $\begin{array}{l}\text { Accessibility } \\
\text { Level }\end{array}$ \\
\hline $\mathbf{0}$ & $\mathbf{1}$ & 0 rules violated: & Accessible \\
$\mathbf{3 3}$ & $\mathbf{4 6}$ & $\begin{array}{l}\text { 1 to } 3 \text { rules } \\
\text { violated: }\end{array}$ & $\begin{array}{l}\text { Marginally } \\
\text { inaccessible }\end{array}$ \\
$\mathbf{1 6}$ & $\mathbf{3}$ & $\begin{array}{l}\text { 4 to 6 rules } \\
\text { violated: } \\
7+\text { rules violated: }\end{array}$ & $\begin{array}{l}\text { Moderately } \\
\text { inaccessible } \\
\text { Substantially } \\
\text { inaccessible }\end{array}$ \\
\hline
\end{tabular}

Table 8 - Comparison of Websites in each of Lazar et al.'s Accessibility Levels

The Lazar et al.'s study found that 92\% (46 out of 50) of the assessed websites were marginally inaccessible. Lazar et al. asserted that this is an encouraging finding because it means that a large portion of web sites could be, "retrofitted for accessibility with a limited effort, as opposed to creating a new site.” (Lazar J. B.-D., 2003) In comparison, $66 \%$ (33 out of 50) of Ontario websites were found to be marginally inaccessible and $34 \%$ (16 out of 50 ) of websites were found to be moderately inaccessible or worse. Lazar et al. suspect that websites in the latter range are much more likely to require an entirely new website to fix accessibility problems. Further they note that, websites with many errors often cite the cost of fixing many different types of WCAG accessibility guidelines as a barrier to implementation. (Lazar J. B.-D., 2003)

\subsubsection{Comparison: Number of Homepages that violated each WCAG priority one} guideline. 
Across guidelines, more Ontario homepages violated WCAG priority level one guidelines than homepages in the Baltimore area. Table 9 below visualizes the differences in how many homepages violated a particular WCAG guideline in the Ontario Study and the Baltimore-area study.

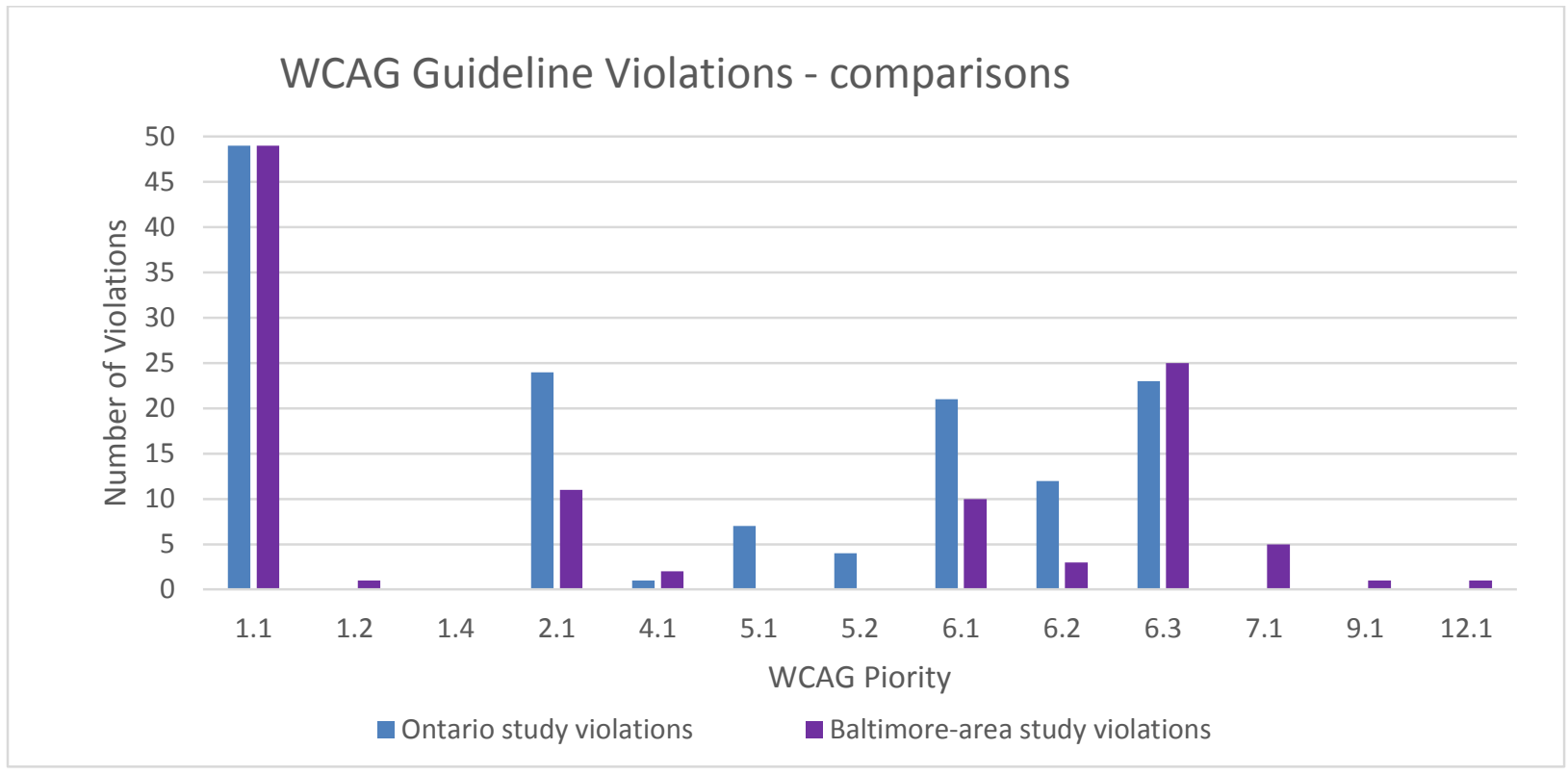

Table 9 -Lazar et al. Number of Homepages which violated WCAG Guidelines

Despite being conducted 16 years later, the Ontario study found 33 more WCAG priority one violations than the Baltimore-area study. In the Ontario study, guidelines 2.1 (information conveyed with color is also available without color), and 6.1 (documents may be read without style sheets) were violated by 13 and 11 more websites than the Baltimore-area study. Guidelines 5.1 (data tables identify row and column headers), 5.2 (data tables use markups for data), and 6.2 (equivalents for dynamic content are updated when the dynamic content changes), also contributed to Ontario's greater number of violations. Table 10 shows the magnitude of difference in the findings of each study. The only WCAG guideline in which Ontario had fewer homepage violations than the Baltimore-area by a significant margin was 7.1 (allow users to control flickering). As will 
be discussed later, there is evidence that this result can be credited to adoption of new technologies by website developers since the Lazar et al. study took place.

\begin{tabular}{|c|c|c|}
\hline WCAG Guideline & $\begin{array}{c}\text { Ontario study } \\
\text { violations }\end{array}$ & $\begin{array}{c}\text { Baltimore-area } \\
\text { study violations }\end{array}$ \\
\hline $\mathbf{1 . 1}$ & 49 & 49 \\
\hline $\mathbf{1 . 2}$ & 0 & 1 \\
\hline $\mathbf{1 . 4}$ & 0 & 0 \\
\hline $\mathbf{2 . 1}$ & 24 & 11 \\
\hline $\mathbf{4 . 1}$ & 1 & 2 \\
\hline $\mathbf{5 . 1}$ & 7 & 0 \\
\hline $\mathbf{5 . 2}$ & 4 & 0 \\
\hline $\mathbf{6 . 1}$ & 21 & 10 \\
\hline $\mathbf{6 . 2}$ & 12 & 3 \\
\hline $\mathbf{6 . 3}$ & 23 & 25 \\
\hline $\mathbf{7 . 1}$ & 0 & 5 \\
\hline $\mathbf{9 . 1}$ & 0 & 1 \\
\hline $\mathbf{1 2 . 1}$ & 0 & $\mathbf{1 0 8}$ \\
\hline & $\mathbf{1 4 1}$ & 1 \\
\hline & & 0
\end{tabular}

\begin{tabular}{|c|}
\hline Difference \\
\hline 0 \\
\hline-1 \\
\hline 0 \\
\hline 13 \\
\hline-1 \\
\hline 7 \\
\hline 4 \\
\hline 11 \\
\hline 9 \\
\hline-2 \\
\hline-5 \\
\hline-1 \\
\hline-1 \\
\hline 33 \\
\hline
\end{tabular}

Table 10 -Degree of Difference between Ontario and Baltimore Study Findings

\subsubsection{Comparison: Average number of violations per organization category}

Figure 3 below displays comparison between the average number of accessibility violations per website category for the WCAG priority level one guidelines.

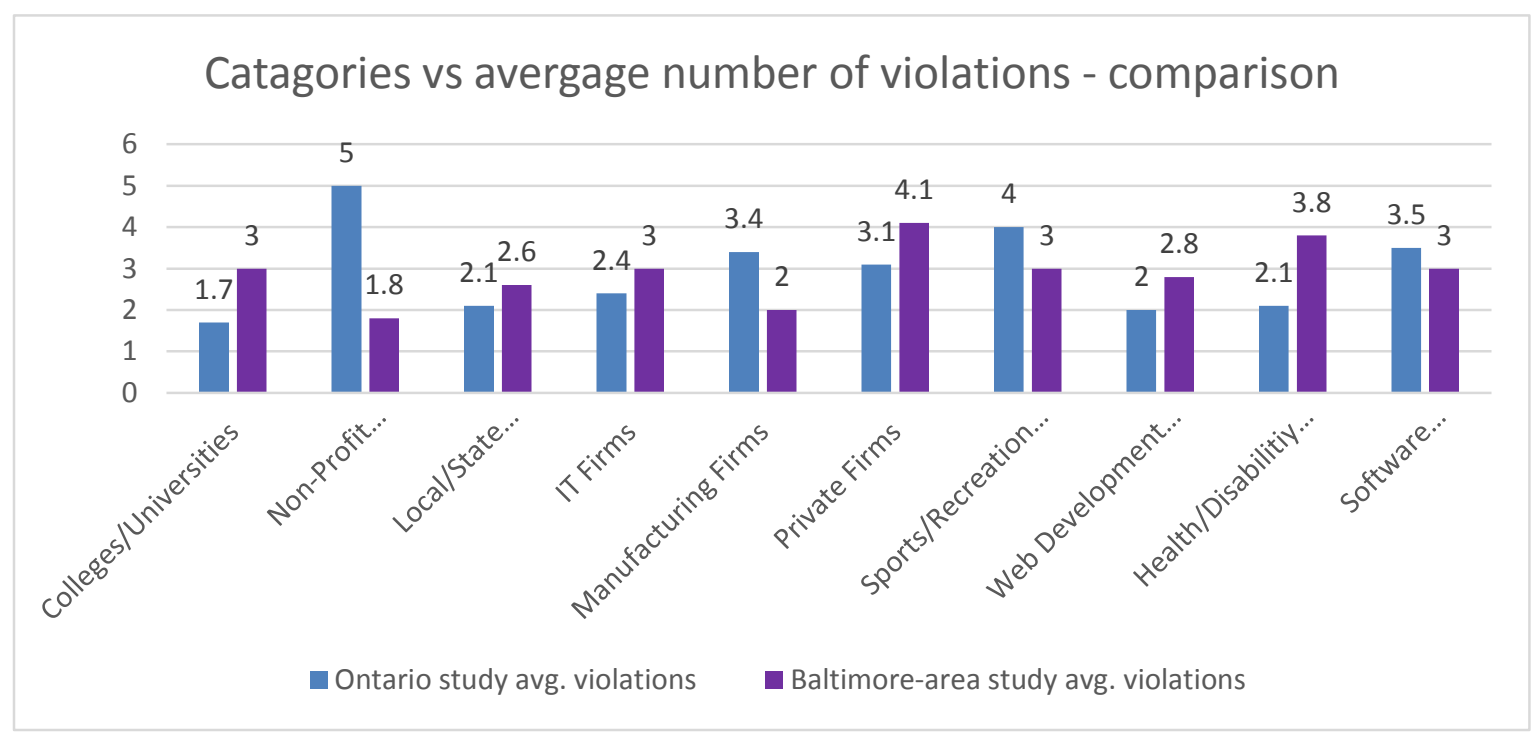

Table 11 - Comparison: Categories vs Avg. Number of Violations 
This comparison shows that homepages for Ontario Non-Profits, Manufacturing

Firms and Sports/Recreation Firms significantly underperform compared to their

Baltimore-area counterparts. Where Non-Profit organizations had the lowest average

violations in the Lazar et al. study they have the highest average number of violations in the Ontario study. As shown in Table 12 below, Ontario Colleges/Universities and

Health/ Disability organizations on average had fewer WCAG violations than those in the Baltimore-area.

\begin{tabular}{|c|c|c|}
\hline Website Category & $\begin{array}{c}\text { Ontario study } \\
\text { Avg. violations }\end{array}$ & $\begin{array}{c}\text { Baltimore-area study } \\
\text { Avg. violations }\end{array}$ \\
\hline Colleges / Universities & 1.7 & 3 \\
\hline $\begin{array}{c}\text { Non-Profit } \\
\text { Organisations }\end{array}$ & 5 & 1.8 \\
\hline $\begin{array}{c}\text { Local/State } \\
\text { Federal, Provincial, } \\
\text { Municipal) }\end{array}$ & 2.1 & 2.6 \\
\hline IT Firms & 2.4 & 3 \\
\hline Manufacturing Firms & 3.4 & 2 \\
\hline Private Firms & 3.1 & 4.1 \\
\hline $\begin{array}{c}\text { Sports/Recreation } \\
\text { Firms }\end{array}$ & 4 & 3 \\
\hline $\begin{array}{c}\text { Web Development } \\
\text { Firms }\end{array}$ & 2 & 2.8 \\
\hline Health/Disability Firms & 2.1 & 3 \\
\hline $\begin{array}{c}\text { Software Development } \\
\text { Firms }\end{array}$ & $\mathbf{3 . 5}$ & $\mathbf{3}$ \\
\hline
\end{tabular}

\begin{tabular}{|c|}
\hline Difference \\
\hline-1.3 \\
\hline 3.2 \\
\hline-0.5 \\
\hline-0.6 \\
\hline 1.4 \\
\hline-1 \\
\hline 1 \\
\hline-0.8 \\
\hline-1.7 \\
\hline 0.5 \\
\hline
\end{tabular}

\begin{tabular}{|c|c|c|}
\hline Mean & 2.93 & 2.91 \\
\hline
\end{tabular}

Table 12 - Comparison: Average number of Violations

\subsubsection{Discussion}

The second part of this studies primary research question asks why some homepages are less accessible than others. This section will explore the possible explanations for the differences between the results of the Baltimore-area study and the 
Ontario study. This includes, differences in legislation, and differences in amount of time organizations have been exposed to WCAG. Following this, the secondary research questions and other potential factors within the findings will be addressed. Overall this will provide a multifaceted analysis of potential factors related to Ontario homepage accessibility.

\subsubsection{Differences in Legislation}

A potential factor involved in difference between findings of the Baltimore and Ontario studies is the different ways WCAG are represented in each area's legislation. An analysis of differences between the representation of WCAG standards in Canada and the U.S. legislation shows that these differences alone do not provide a strong explanation for the better compliance of Baltimore websites in 2003 than the Ontario websites from 2017. Ontario's primary web accessibility legislation is the AODA, and in the U.S. this is the federal Section 508 regulations. Both laws use the WCAG as a basis for legal standards of website accessibility. Analysis show that Ontario's AODA explicitly enshrines all of the WCAG standards into law, while the U.S. legislation form 2003 only enshrines some of the WCAG standards as law. (Accessibility for Ontarians with Disabilities Act, 2005) (Program, Accessed July 2017) Despite Ontario having more fulsome legal representation of WCAG standards, its websites were found to be less compliant with WCAG than those of the Baltimore study from 2003. The following section explores differences in how the WCAG were incorporated and expressed in the AODA and Section 508 as possible explanations for the resulting web accessibility scores. 


\subsubsection{WCAGs represented in United States Section 508}

In 2003, Section 508 required that U.S. websites conform with only some WCAG priority one rules. Website accessibility rules are referenced in Section 508 of the U.S. Rehabilitation Act, the Workforce Investment Act of 1998 and section 255 of the Communications Act. In most literature, including the Lazar et al. study, the Section 508 regulations are considered the primary web accessibility legislation in the U.S. (Lazar J. B.-D., 2003) In 2017, the United States Access Board (USAB) (United States Access Board., 2018) did update the Section 508 standards around website accessibility. According to the USAB, the previous rules around website accessibility in Section 508 are less explicit than WCAG 2.0's Success Criteria for web accessibility, and as such needed to be updated to reflect all of the WCAG's recommendations. (United States Access Board., 2018) The W3C initiative notes that the WCAG Success Criteria are written so as to be objectively testable, technology neutral, and applicable to a wide range of content types and formats. (W3C Web Accessibility Initiative, 2005) The Section 508 guidelines specifically outline standards for computer hardware and software, websites, multimedia such as video, phone systems, and copiers but do not cover all potential website formats or features. As a result not all WCAG were incorporated into these laws. (United States Access Board., 2018) See in Appendix B the USAB's table comparing the WCAG 2.0 Success Criteria and the corresponding requirements in the existing 508 Standards. The USAB notes that WCAG 1.1, 1.2, 1.4, 2.1 and 4.1 are either directly represented or found to be "substantially equivalent," to Section 508 rules. This means that for the specific technology addressed in Section 508, the standards are the same as those outlined in the WCAG guidelines. However for WCAG 5.1, 5.2, 6.1, 6.2, 6.3, 7.1, 
9.1, and 12.1, Section 508 may have related content but it does not explicitly express those standards as law. Where organizations have a legal obligation to meet the standards for WCAG guidelines 1.1, 1.2, 1.4, 2.1 and 4.1, this may help explain better compliance with those guidelines in the Baltimore study.

\subsubsection{WCAGs represented in the AODA}

The AODA explicitly references all of the WCAG 2.0 as the standards for website accessibility in Ontario. This implementation is consistent with the later Johan decision which required the federal government to update its standards to meet the WCAG. AODA sections 6 and 7 gives authority for the Minister to develop standards for the purpose of website accessibility. (Accessibility for Ontarians with Disabilities Act, 2005) The AODA establishes that in Ontario, "all organizations with 50 or more employees that create new internet websites and web content on those sites must conform with WCAG 2.0 Level A," by of January 1, 2014. The AODA does not reference each WCAG individually, instead the policy on web accessibilities standards is that Ontario websites must meet the established WCAG. (Accessibility for Ontarians with Disabilities Act, 2005) Since Ontario has been using these standards as its policy since 2005, Ontario websites in this study could be expected to have a high degree of compliance with the WCAG standards. However, this study found that on average the websites in the Baltimore study were more compliant with WCAG than those in Ontario. This suggests that the degree to which standards are represented in legislation does not provide a sufficient explanation of Ontario's lower rate of compliance. 


\subsubsection{Differences in amount of time exposed to WCAG}

Section 508 legislation was introduced in 2001 with Lazar et al.'s study taking place in 2003. AODA legislation came into effect in 2005 while the Ontario study was conducted in 2017. Despite Ontario organizations being legally required to conform with WCAG for 10 more years, they were found to be on average less accessible than those in the Baltimore area. As noted, one motivating factor for Lazar et al. to conduct their study which built upon Sullivan's work from 2000, was to see if 2 years of exposure to web accessibility legislation had led to websites becoming more accessible. While not directly addressing the factor of amount of time exposed to WCAG, follow-up research from Lazar et al. proposed that there may be a relationship between the age of a website and its level of accessibility. In a study from 2006, Lazar and Greenidge found that websites tend to decline in accessibility over time. (Lazar J. a., 2006) According to their research, new versions of websites are often an update to an existing page and not rebuilt from scratch. In this process, previous accessibility errors are often not addressed. (Lazar J. a., 2006) If websites in Ontario tended to be older than those in the Baltimore area, this could help to explain the lower level of accessibility despite longer exposure time. Regardless neither differences in legislation nor differences in exposure time sufficiently explain the results of the Ontario study.

\subsubsection{Factors Related to Website Accessibility - Secondary research questions}

This section examines potential factors related to homepage accessibility that can be extrapolated from the Ontario study's data. Issues raised during the literature review prompted additional research questions for this study to address. These questions act as leads for potential factors related to levels of website accessibility. 
These questions were:

1. Are the findings of the Ontario study consistent with other research on website accessibility?

2. Are government and web developer websites more accessible than the average?

3. Are rural libraries less accessible than urban libraries?

4. Are French website more or less accessibility than English websites?

5. Is there a significant difference in Web Accessibility between Federal, Provincial and Municipal websites?

6. How do changes in technology impact the evaluation of Ontario websites?

7. What is the impact of WCAG violation 6.3 (Requirement for Javascript)?

\subsubsection{Are the findings of the Ontario study consistent with other research on website accessibility?}

Previous research suggested that factors within a website design could have a relationship to a website's overall level of accessibility. Analysis of the Ontario data showed that this research has at least surface level validity with the finding of this previous work. Specifically, relationships between variables in research from Thompson et al. were also found in the Ontario study. Thompson et al. operationalized the variable of overall accessibility as the number of references and links a website has to an accessibility policy. Their study asked, "which independent variables are the best predictors of web accessibility?" (Thompson T. C., 2013) They found that, "the inclusion of alt text with images and labeled input fields," (Thompson T. C., 2013) were the strongest predictors of variance in having an, "accessibility link on their home page." (Thompson T. C., 2013) In order to compare these findings with the Ontario study some 
mapping of variables was required. When mapped, analysis showed that relationships between variables in the Ontario study were consistent with the Thompson et al.'s conclusion. Specifically, statistical analysis of the Ontario study revealed that, websites missing alternative text for images were more likely to have a link to an accessibility policy.

For comparison, Thompson et al.'s variables, "inclusion of alt text with images," and "labeled input fields," were mapped to WCAG guidelines 1.1 (image missing alternative text) and 5.1 (headers not identified in data tables). In the study of Ontario websites, additional data was collected to indicate whether a homepage had a listed accessibility policy or a link to an accessibility policy. These variables had enough surface validity be sufficiently similar for exploring whether there was a relationship between these WCAG priority level one rules and the inclusion of an accessibility link in the Ontario sample. In order to explore the prediction power of guidelines 1.1 and 5.1 on links to accessibility policy, the dataset of findings from the Ontario study was transferred to IBM's SPSS software. In this case, the independent variables of conformance to WCAG 1.1 and 5.1 were compared to an indicator of whether or not a homepage listed or linked to an accessibility policy. In a linear regression, WCAG 1.1 was run as an independent variable ( $1=$ violation, $0=$ indicating no violation) against the dependent variable of whether a homepage had a listed accessibility policy or a link to an accessibility policy $(1=$ listed or linked, $0=$ not listed or linked $)$ This was done to determine if, an image missing alternative text was a statistically significant predictor of linking to an accessibility policy. The test produced an R squared of $2.4 \%$ variance explained with an ANOVA significance of 0.286 . The Standardized coefficient shows a 
0.155 magnitude or a moderate positive relationship. (See table 13)

\begin{tabular}{|c|c|c|c|c|c|c|c|c|}
\hline \multicolumn{9}{|c|}{ Coefficients $^{a}$} \\
\hline \multirow[b]{2}{*}{ Model } & & \multicolumn{2}{|c|}{ Unstandardized Coefficients } & \multirow{2}{*}{$\begin{array}{c}\begin{array}{c}\text { Standardized } \\
\text { Coefficients }\end{array} \\
\text { Beta }\end{array}$} & \multirow[b]{2}{*}{$t$} & \multirow[b]{2}{*}{ Sig. } & \multicolumn{2}{|c|}{$95.0 \%$ Confidence Interval for B } \\
\hline & & B & Std. Error & & & & Lower Bound & Upper Bound \\
\hline 1 & (Constant) & $6.830 \mathrm{E}-018$ & .503 & & .000 & 1.000 & -1.010 & 1.010 \\
\hline & 1.1 & .551 & .508 & .155 & 1.085 & .283 & -.470 & 1.572 \\
\hline
\end{tabular}

a. Dependent Variable: AccessLINK

Table 13 - Correlation between "image missing alternative text " and "link to accessibility policy"

A linear regression using WCAG 5.1 as an independent variable was separately run against whether a homepage had a listed accessibility policy or a link to an accessibility policy. The test produced an R squared of .8 \% (less than $1 \%$ ) variance explained with an ANOVA significance of 0.533. The Standardized coefficient shows a 0.09 magnitude or a weak negative relationship. (See table 14 below)

\begin{tabular}{|c|c|c|c|c|c|c|c|c|}
\hline \multicolumn{9}{|c|}{ Coefficients $^{a}$} \\
\hline \multirow{2}{*}{\multicolumn{2}{|c|}{ Model }} & \multicolumn{2}{|c|}{ Unstandardized Coefficients } & \multirow{2}{*}{$\begin{array}{c}\begin{array}{c}\text { Standardized } \\
\text { Coefficients }\end{array} \\
\text { Beta } \\
\end{array}$} & \multirow[b]{2}{*}{$t$} & \multirow[b]{2}{*}{ Sig. } & \multicolumn{2}{|c|}{$95.0 \%$ Confidence Interval for B } \\
\hline & & $B$ & Std. Error & & & & Lower Bound & Upper Bound \\
\hline 1 & (Constant) & .558 & .077 & & 7.225 & .000 & .403 & .713 \\
\hline & 5.1 & -.130 & .206 & -.090 & -.628 & .533 & -.545 & .286 \\
\hline
\end{tabular}

a. Dependent Variable: AccessLINK

Table 14 - Correlation between, "headers not identified in data tables" and "link to accessibility policy"

Further, a regression involving all measured WCAG priority level one violations revealed that 1.1 and 5.1 had the highest Beta values for explaining variance within the dependent variable of linking to an accessibility policy. This analysis shows that the findings of the Thompson et al. study were consistent for the Ontario study. Specifically, that the inclusion of alt text with images and labeled input fields were both the strongest predictors of variance in having an accessibility link on a webpage when compared to the other variables. Interestingly, an exclusion of alt text with images positively predicted a moderate amount of variance in whether a site linked to accessibility, while exclusion of 
labeled input fields negatively predicted this variance. This means that for this sample, websites missing alternative text for images were more likely to have a link on accessibility, while homepages missing labeled input fields were less likely to have a link on accessibility. Due to a high F value and small sample size (50 total), these results are not considered to be statistically significant, and this relationship is not considered generalizable to a larger population. This finding is further limited by the surface validity of variable mapping and other potential factors not explored in the comparison of each studies' findings. So while this is an interesting result, the above analysis provides limited explanation of potential factors related to a website's level of accessibility.

\subsubsection{Are government and web developer websites more accessible than the}

\section{average?}

Homepages in Lazar et al.'s study were categorized by organization because different sectors of society may have different expectations regarding their adoption of web accessibility guidelines. For example, one might expect government or health websites to act as, "leaders," and have websites that are relatively more accessible as the bodies than enacted these guidelines. (Lazar J. B.-D., 2003) Similarly, one may expect software development firms and web development firms to have a relatively greater expertise in website development and as a result have fewer WCAG violations. (Lazar J. B.-D., 2003) In the Ontario study, these expectations prove to be accurate for government, health and web development websites. While in the Baltimore-area study, these expectations are correct for government and web development websites. For the remaining categories of websites, the average number of violations for these websites is at or above the average for all websites that were assessed. (See Table 15) 


\begin{tabular}{|c|c|c|}
\hline Website Category & $\begin{array}{c}\text { Ontario study } \\
\text { average } \\
\text { violations }\end{array}$ & $\begin{array}{c}\text { Baltimore-area } \\
\text { study average } \\
\text { violations }\end{array}$ \\
\hline $\begin{array}{c}\text { Local/State } \\
\text { (Federal, Provincial, Municipal) }\end{array}$ & 2.1 & 2.6 \\
\hline Health/Disability Firms & 2.1 & 3.8 \\
\hline Average for all websites: & $\mathbf{2 . 9 3}$ & $\mathbf{2 . 9 1}$ \\
\hline
\end{tabular}

\begin{tabular}{|c|c|c|}
\hline Web Development Firms & 2 & 2.8 \\
\hline Software Development Firms & 3.5 & 3 \\
\hline Average for all websites: & $\mathbf{2 . 9 3}$ & $\mathbf{2 . 9 1}$ \\
\hline
\end{tabular}

Table 15 - Specific Categories vs. the Average Number of Violations

For both studies, Software Development Firms had an above-average number of violations. While no academic evidence could be found that explains this finding, a conversation with website accessibility consultant David MacDonald provided one potential explanation. MacDonald explained that for Software Firms, their homepage often acted as a resume for potential clients which tended to favor visual appeal over accessibility. (Macdonald, November 18, 2017. 3:30 - 4:00 pm) While not conclusive, MacDonald asserted that this was part of a larger trend where many websites are changing their format to account for Smartphone browsing.

\subsubsection{Comparison between urban and rural library website accessibility}

In work by Rosenau, it was found that rural communities suffered disproportionate access to services for persons with disabilities. (Rosenau, 2010) From this premise it could be assumed that rural organizations may have less accessible websites than urban organization. In the sampling of websites, Ontario libraries in rural and urban communities were selected in order to test this finding as a factor in website accessibility. Libraries were specifically selected as public institutions with the expectation that their services should be accessible to all members of the community. 
(Toronto Public Library, Accessed 2017) Evaluations of the rural Burke's Falls Library and the urban Toronto library were consistent with this assumption. (See Table 16)

\begin{tabular}{|c|c|c|}
\cline { 2 - 3 } \multicolumn{1}{c|}{} & $\begin{array}{c}\text { Burke's Falls } \\
\text { Public Library }\end{array}$ & $\begin{array}{c}\text { Toronto } \\
\text { Public Library }\end{array}$ \\
\hline \# of WCAG priority one violations & 3 & 1 \\
\hline Average for all websites: & \multicolumn{2}{|c|}{2.93} \\
\hline
\end{tabular}

Table 16 - Comparison of Rural and Urban Library Homepages

The Toronto Public Library serves the largest population in Ontario while the Burke's Falls Library services a population of 967 people with a population density of 309.9 fitting the definition of a rural village in Canada. (Statistics Canada, 2011) Lazar et al.'s methodology allows for discretion in the selection of websites so long as the websites were selected from ranked lists that indicate a significant level of influence on society.

(Lazar J. B.-D., 2003) In this, the selection of library websites allows for a deeper dive into the principles of website accessibility while not significantly biasing the results of the overall study. The Burke's Falls Library website failed on criteria 6.1 for not having a text description of an
The Library will remain closed until all repairs have been completed.

We are sorry for the inconvenience this delay may have caused.

For further information you can:

email: burksfallslibrary@gmail.com

Phone: 705-382-3138

Figure 1 - Burke's Falls Library image November 22nd 2017 image that would not be available when style sheets are turned off. This is important because several accessibility devices, such as screen readers, rely on text-equivalents of images in order to describe the features of a website to persons who are blind or vision impaired. In this case, the violation was the above image, which indicates that the library will be closed until repairs have been completed. The message on this image would not be detected by a text reader and this information was not available anywhere else on the website. This is one example of the significance of a WCAG priority one violation, where 
a person who could not view this image would not have received this information and would not know that the library was closed, why it was closed, how long it was closed, or who to contract for more information. With regard to differences between urban and rural website accessibility, it is unclear if this problem was a result of the concerns raised in previous research by Rosenau. More analysis would need to be done to see if violations were a result of, "lack of resources, funding or experts in web development services," for the Burke's Falls Library. (Rosenau, 2010)

\subsubsection{Are French websites more or less accessibility than English websites?}

The only sampled website which uses French as the primary language came from La Cité Collégiale. La Cité's website contained 4 types of WCAG priority one violations. The other 49 English sites on average contained 2.8 of priority one violations. Although it is impossible to generalize, in this one example it appears that the La Cité website is less accessible when compared to the average of English websites. In the Canadian context, more research should be conducted that explores factors related to the primary language of websites. The University of Ottawa, CBC Radio and Ontario.ca were the only websites to have an equal presence of both English and French on their homepages. Significantly, all of these pages passed criteria 4.1 where changes in the primary language must be indicated in the HTML code of an image or object description. This lets the reader know that the primary language of an image is French before the French description is provided or the primary language is English before an English description is provided. These 
bilingual websites were good anecdotal examples of homepages with successful compliance to WCAG priority level one guidelines.

\subsubsection{Is there a significant difference in Web Accessibility between Federal, Provincial and Municipal websites?}

Lazar et al.'s study did not examine U.S. websites at the federal level for compliance with WCAG. In the Canadian context, both the Federal and Provincial governments have issued legislation which requires compliance with WCAG. In the sampling for the Ontario study, homepages for the federal and provincial governments as well as the city of Ottawa were selected.

\begin{tabular}{|c|c|c|c|}
\cline { 2 - 4 } \multicolumn{1}{c|}{} & $\begin{array}{c}\text { Federal } \\
\text { (Canada.ca) }\end{array}$ & $\begin{array}{c}\text { Provincial } \\
\text { (Ontario.ca) }\end{array}$ & $\begin{array}{c}\text { Municipal } \\
\text { (Ottawa.ca) }\end{array}$ \\
\hline \# of WCAG priority one violations & 2 & 1 & 5 \\
\hline Average for all websites: & \multicolumn{3}{c}{} \\
\hline
\end{tabular}

Table 17- Comparison of Federal, Provincial and Municipal Homepages

The homepage for Ontario proved to be the most compliant among websites representing each level of government. Interestingly, out of all 50 organizations, Ontario.ca was the only homepage that did not violate WCAG 1.1 (image missing alternative text). While no website was perfectly compliant, the Ontario homepage was also 1 of 10 sampled websites that only violated 1 WCAG priority level one rule. Overall, this suggests that the Ontario government's website can be made compliant with relatively less work than the Federal and Municipal webpages.

\subsubsection{How do changes in technology impact the evaluation of Ontario websites?}

One finding in the Ontario study's data can be potentially explained by the impact of changing technology from the time of the Baltimore area study. In the Baltimore-area study, 5 websites violated guideline 7.1 and in the Ontario study, no websites violated guideline 7.1. Research and advice from a professional web developer suggest that this 
finding is evidence of the web development industry's adoption of this guideline. Flickering is caused when objects on a website flash, stutter or blink. (W3C Web Accessibility Initiative, 2005) This can cause disruptions for users with certain disabilities, such as epilepsy or a sensitivity to light. Lazar et al.'s guide for manual testing of guideline 7.1 states that:

- Content on the Web pages should not cause any onscreen flickering; and

- Certain elements on a Web page (e.g., scripts, applets, movies, animated gifs, etc.) may cause on-screen flickering. (Lazar J. B.-D., 2003)

In manual testing, all websites passed guideline 7.1 Flicker should be avoided. In order to reconcile this finding, I contacted David MacDonald who is a professional website accessibility consultant in Ontario. His opinion was that, "Flickering is an almost nonexistent problem in modern website design." (Macdonald, November 18, 2017. 3:30 4:00 pm) Since the WCAG 1.0 guidelines were developed, "website design techniques have progressed and most would not create the conditions that induce flickering on website objects." (Macdonald, November 18, 2017. 3:30 - 4:00 pm) In comparison, 5 out of 50 websites that Lazar et al. studied failed on guideline 7.1 in 2003 . While more research could be directed at this finding, MacDonald's opinion does offer one plausible explanation for the perfect compliance rate of all websites in the Ontario study.

\subsubsection{What is the impact of WCAG violation 6.3. (Requirement for Javascript)?}

Unlike most other WCAG priority level guidelines, a violation of 6.3 (Ensure that pages are usable when scripts, applets, or other programmatic objects are turned off or not supported.) can mean that no users are able to access website content. (W3C Web Accessibility Initiative, 2005). Research suggests JavaScript is the programming 
language that is most often used for enhancing webpage interactivity and functionality. (Yue, 2009) Some debate exists within the web developer community on whether or not the requirement for websites to have Javascript enabled is significant barrier to accessibility. If the vast majority of internet users browse with Javascript enabled, WCAG 6.3 relevant to the evaluation of a website's accessibility?

$42 \%$ of Ontario homepages violated WCAG 6.3 (Ensure that pages are usable when scripts, applets, or other programmatic objects are turned off or not supported.) In this study, these websites were considered less accessible because they were less usable when Javascript was disabled. Reliable data on the percentage of internet users that browse with Javascript disabled is difficult to find. According to the developers of the web accessibility testing software WebAIM, Javascript effects accessibility in four areas: Website navigation, Hidden content, User control, and Lack of user control over automated content changes. (WebAIM, 2010) Some sources suggest that a requirement for Javascript effects a relatively small percentage of internet users. According to a blog post by then Chief Operating Officer of Yahoo! Jerry Yang, their web analytics team calculate that only $1.4 \%$ of internet users in the European Union and $3.05 \%$ of users in the U.S. browse with Javascript disabled, however their sources for this data were unavailable. (Yang, 2006) In his post, Yang notes that requiring JavaScript to view a website will definitely limit number of potential users. However he postulates that, "the majority of users you want to use your site will have JavaScript enabled.” (Yang, 2006) Further he notes that users that do not have Javascript enabled are likely using corporate or workplace computers. (Yang, 2006) 
Another Yahoo! blog post places the ratio of users who browse with Javascript disabled at a much higher figure. According to Yahoo's research from 2006, 10\% of internet users in the U.S. browse without Javascript enabled. (Ried, 2010) In the Ontario study, Bell Media and Ontario.ca's homepages were the examples of websites that were not usable without Javascript enabled. When Javascript was disabled for Bell Media's webpage, a blank screen appeared with no visible content. For Ontario.ca, an image appeared in both English and French that Javascript was required to view this site. In the case of Ontario.ca, a user would be able to understand why they could not view the webpage's content as the image contains a text description of its content. (See Figure 2) However for Bell Media, no information on the website would be available if Javascript is not turned on or available.

\section{Pontario}

JavaScript is required to view this site

Ontario.ca needs JavaScript to function properly and provide you with a fast, stable experience.

Please enable Javascript or check your browser's settings.

\section{JavaScript est nécessaire pour ce site}

Le site Ontario.ca exige JavaScript pour fonctionner comme il faut, avec rapidité et stabilité. Veuillez activer JavaScript ou vérifier

les paramètres de votre navigateur.

Figure 2 - Ontario.ca Image When Javascript is Disabled

Gibson and Schwerdtfeger conducted research for IBM on accessibility barriers created by Javascript. According to them, there are several reasons why a user might browse websites without Javascript, including reducing data consumption and increasing website download speeds. (Gibson, 2005) In addition, certain devices may require that Javascript be disabled. For example Kindle web-readers and screen-reader devices often require that websites have a non-Javascript version in order to these devices to access and 
transmit their content. (Gibson, 2005) Some disabled users have difficulty using a mouse to manipulate websites and require that websites be accessible through keyboard-only access. (W3C Web Accessibility Initiative, 2005) At the time of their research in 2005 one source noted that $50 \%$ of websites on the internet used Javascript. (E-Soft, Inc.,, 2004) Regardless of the percentage of users that browse without Javascript enabled, all sources agree that a website requiring Javascript will be inaccessible to some users. As noted above, several devices that accommodate disabled users require non-Javascript versions of websites in order for users to access content. Taken together WCAG 6.3 seems to be a strong measure of a webpage's level accessibility.

Overall the analysis of WCAG 6.3 is part of a larger argument as to the effectiveness of the WCAG. Although WCAG 2.0 is a well-recognized standard, they are not based on empirical research. (Termens, 2009) Termens research is a reminder that web accessibility guidelines only address a portion of what makes a website accessible. In the conclusion, the reasons for conducting this research will be revisited. Areas where research questions may have fallen short of addressing issues in website accessibility evaluations will be explored.

\section{Chapter: Conclusion}

\subsection{Conclusions on the Secondary Research Questions:}

This study found that despite a difference of 16 years between evaluations, on average Ontario websites are less accessible and have more accessibility violations than those in the Baltimore-area study. The time between these evaluations was found to not sufficiently explain these finding. From this, secondary research questions explored other 
potential factors related to a website's level of accessibility. These explorations found that some internal factors were related to a website's overall level of accessibility. Several anecdotal finding and future pathways for research were identified.

While the above conclusions focus on only a small sample of Ontario websites, this study's findings do provide a foundation for similar research in other Canadian provinces. In particular, an updated evaluation of websites using WCAG 2.0 would help to better assess barriers to accessibility in Canada. As noted by Termens, "WCAG 2.0 is not tied to any specific technology and leaves a wide margin for future technologies." (Termens, 2009) Furthermore, WCAG 2.0's evaluation criteria for websites extends to all types of virtual communication and interactive multimedia content. (Termens, 2009) One area not considered by this study was the accessibility of web pages on mobile devices. The W3 Consortium indicates that technology development is increasingly moving towards mobile, tablet and other non-traditional technology. (World Wide Web Consortium, Accessed September 2017) These types of devices should certainly be factored into future research on website accessibility.

This study also found that many issues around website accessibility lack academic analysis. Specifically debates on, whether or not accessibility guidelines are beneficial to all users, whether internal website features are related to overall levels of accessibility, trends in current and future website design, and accurate analysis of the ratio of internet users that browse without Javascript. The Ontario study did not address issues raised in the review of literature around implementation. Future work should follow-up on Braknik et al.'s suggestion that more accessibility training is required both for industries and for the public. (Brajnik, Testability and validity of WCAG 2.0: the expertise effect. , 2010) 
For example, in the Netherlands the government uses a National Urgency Program to support municipalities in the process of implementing accessibility guidelines. (Velleman, 2015) Importantly, a unified approach across research on website accessibility is required advance this school of thought. The value of research into website accessibility is its ability to improve outcomes for all users. 


\section{Appendices}

\section{Appendix A - Research and Search Methodology}

1) Use of research librarians at key data stores;

2) Databases including: DBLP, Google Scholar, ISI Proceedings, JSTOR Search, Medline, Scopus, and Web of Science;

3) Foundational journal article on the subject of Web Accessibility (Parmanto, 2010);

4) Google scholar searches for most cited articles related to the following topics of (With a bias towards recency):
a. AODA reports;
b. Website accessibility; and
c. W3C website accessibility standards.

5) Carleton University library searches for available literature; and

6) Correspondence Website Accessibility consultant.

For each article or report I analyzed the approaches, limitations, and conclusions while collecting content. I attempted to identify methodological problems, and point out research gaps.

The objective of a review of literature is to inform the reader of:

- the major achievements in the reviewed field;

- the main areas of debate, and

- the outstanding research questions. 


\section{Appendix B - Web Content Accessibility Guidelines (WCAG) Priority}

\section{Level One}

1.1 Provide a text equivalent for every nontext element (e.g., via "alt," "longdesc," or in element content). This includes images, graphical representations of text (including symbols), image map regions, animations (e.g., animated GIFs), applets and programmatic objects, ASCII art, frames, scripts, images used as list bullets, spacers, graphical buttons, sounds (played with or without user interaction), stand-alone audio files, audio tracks of video, and video.

1.2 Provide redundant text links for each active region of a server-side image map.

1.3 Until user agents can automatically read aloud the text equivalent of a visual track, provide an auditory description of the important information of the visual track of a multimedia presentation.

1.4 For any time-based multimedia presentation (e.g., a movie or animation), synchronize equivalent alternatives (e.g., captions or auditory descriptions ofthe visual track) with the presentation.

2.1 Ensure that all information conveyed with color is also available without color, for example from context or markup.

4.1 Clearly identify changes in the natural language of a document's text and any text equivalents (e.g., captions).

5.1 For data tables identify row and column headers.

5.2 For data tables that have two or more logical levels of row or column headers, use markup to associate data cells and header cells.

And if you use frames (Priority one)

6.1 Organize documents so they may be read without style sheets. For example, when an HTML document is rendered without associated style sheets, the document must still be readable.

6.2 Ensure that equivalents for dynamic content are updated when the dynamic content changes.

6.3 Ensure that pages are usable when scripts, applets, or other programmatic objects are turned off or not supported. If this is not possible, provide equivalent information on an alternative accessible page. And if you use multimedia (Priority one) 
7.1 Until user agents allow users to control flickering, avoid causing screen flicker.

9.1 Provide client-side image maps instead of serverside image maps except where the regions cannot be defined with an available geometric shape.

And if you use tables (Priority one)

11.4 If, after best efforts, you cannot create an accessible page, provide a link to an alternative page that uses $\mathrm{W} 3 \mathrm{C}$ technologies, is accessible, has equivalent information (or functionality), and is updated as often as the inaccessible (original) page.

12.1 Title each frame to facilitate frame identification and navigation. And if you use applets and scripts

(Priority one)

14.1 Use the clearest and simplest language appropriate for a site's content. And if you use images and image maps (Priority one)

(from: http://www.w3.org/TR/WCAG10/full-checklist.html)

\section{Appendix C - Lazar et al.'s Guide to Manual Website Checks for WCAG Priority Level One Guidelines}

WCAG Guideline 2.1 prohibits the use of color as the sole method for indicating information on a Web page. Therefore, we checked each page to ensure that all information expressed through the use of color is also available without color. The rationale behind the need for manual checks is that when colors are used as the sole method for identifying screen elements or controls, persons who are color blind as well as those people who are blind or have low vision may find the Web page unusable. This provision does not prohibit the use of color to enhance identification of important features. It does, however, require that some other method of identification, such as text labels, be combined with the use of color. WCAG 6.1 and Section 508 (d) deal with style sheets that require testing. The software tools may flag any page that includes style sheets as a possible accessibility problem. However, two tools - A-Prompt and InFocus 
- interpret this differently. For instance, A-Prompt flags as inaccessible any sites that have an associated style sheet. In contrast, InFocus does not flag as inaccessible any sites that have style sheets. Therefore, this guideline required a manual check. The researchers compared each site with the associated style sheet disabled to the site with the style sheet enabled. Although the layout might look different, as long as the same content, information, and links were readable and apparent on the page, this was not flagged as an accessibility problem. Accessibility problems were flagged when the content and/or functionality of a site was unavailable or unreadable (for instance, when disabling a style sheet caused all the foreground text and background color to become the same color).

Another manual check is required when a page contains data and/or layout tables because it is possible that it may not linearize properly. Paragraphs (g) and (h) of the Section 508 standards require that tables be coded according to the rules for developing tables of the markup language used. It is necessary to check the page to ensure that it can be read in a linear fashion, as this is how assistive technologies render them. Standards that define the proper usage of tables are being currently developed. It is possible to see what a page looks like with tables linearized by selecting the "Linearized preview" option from the Preview menu bar in InFocus. A tester can look at the content to see if it makes sense when read from top to bottom.

All of the tables used in the homepages that we checked used layout tables and no data tables. While there are clear methods for providing appropriate labeling on the data tables (using $<\mathrm{TH}>$ tags), the guidelines are not so clear for layout tables. While it would 
be ideal to eliminate the use of table structures for page layout [9] and use table structures only for presenting data, this goal is years away.

Data tables are used so frequently for Web page layout that we believe the current goal should be to provide useful information to the user on how the table is being used for layout. While the HTML 4.01 standards provide methods for labeling tables used for layout (such as $<$ caption $>$, $<$ summary $>$, $<$ abbr $>$, and $<$ axis $>$ [9]), unfortunately current browsers do not support these methods [8]. After vigorous debate, we felt that it would be unreasonable to expect Web designers to include tags that are incompliant with a majority of browsers, and therefore we decided not to mark as inaccessible sites that used tables for page layout. Requirements for Paragraph (c) under Section 508 guidelines are the same as W3C Guideline 2.1 (Color Check), and Paragraph (d) for Section 508 is the same as W3C Guideline 6.1 (Usage of Style Sheets), so these manual check results are the same.

WCAG Priority level one manual checks generated by A-Prompt:

- Guideline 2.1 Color usage (do not use color alone) (11)

- Guideline 4.1 Language changes not indicated (2)

- Guideline 6.1 Style sheets require testing (10)

- Guideline 6.2 Text equivalents require updating (3)

- Guideline 6.3 Programmatic objects require testing (6.3)

- Guideline 7.1 Flicker should be avoided (5) 


\section{Guideline 2.1 Color usage (do not use color alone)}

- Make sure that color alone is not used to convey information. Thus, for instance, data should be presented not only in a color-coded pie chart but also in a data table. Differences in items should not be identified using color alone.

- Ensure that the only factor that differentiates a hyperlink from normal text is not the color.

- We have considered those hyperlinks inaccessible for which the underlining appears only on mouseOver.

- Avoid background colors and images that make it hard to differentiate between them and the text.

\section{Guideline 4.1 Language changes not indicated}

- All words not in the primary language of the document should be identified. Example: “In Luis Bunuel's 1967 film “Belle du Jour,” the stunning . . .” (taken from A-Prompt online help).

- Changes should be indicated in the language through HTML markup. To solve the previous example, the HTML markup would be as follows: In Luis Bunuel's 1967 film $<$ SPAN lang="fr" $>$ "Belle du Jour" $</$ SPAN $>$, the stunning . . . .

\section{Guideline 6.1 Style sheets require testing}


- Make sure that documents are fully accessible even if style sheets are disabled or not supported by certain browsers.

- Provide text equivalents for all images and text generated by style sheets.

- If using a border as a visual means of indicating a structure, make sure that a nonvisual means is also used to convey this structure.

\section{Guideline 6.2 Text equivalents require updating (Ads and Program objects)}

- Whenever dynamic content is updated, Web content developers must also update all text equivalents.

- For all programmatic objects (e.g., applets, scripts, etc.), a text equivalent must be displayed if the programmatic object cannot be viewed. The text equivalent must be updated each time the programmatic object is changed.

\section{Guideline 6.3 Programmatic objects require testing}

- Web documents must be fully accessible and usable when programmatic objects are disabled. The programmatic objects should be removed from the page to verify that it is still usable.

- To ensure that information remains available when scripts, applets, and other programmatic objects are disabled or not supported, accessible alternatives or links to text-based pages with equivalent content should be provided.

- If a page is not accessible without functional scripts, a text equivalent using the NOSCRIPT element must be provided. 


\section{Guideline 7.1 Flicker should be avoided}

- Content on the Web pages should not cause any onscreen flickering.

- Certain elements on a Web page (e.g., scripts, applets, movies, animated gifs, etc.) may cause on-screen flickering.

\section{Appendix D - United States Accessibility Board: WCAG 2.0 Guidelines}

\section{and Section 508 differences:}

\begin{tabular}{|c|c|c|c|c|}
\hline \begin{tabular}{|c|} 
Proposed \\
(WCAG 2.0 \\
Success Criteria \\
[Level] $)$
\end{tabular} & $\begin{array}{c}\text { Existing } 508 \\
\text { Corresponding } \\
\text { Provision } \\
\end{array}$ & Summary & $\begin{array}{c}\text { What would } \\
\text { Change } \\
\end{array}$ & Comment \\
\hline $\begin{array}{l}1.1 .1 \text { Non-text } \\
\text { Content }[\mathrm{A}]\end{array}$ & 1194.22(a) & $\begin{array}{l}\text { Provides for text alternatives } \\
\text { of images and other non-text } \\
\text { content, including user } \\
\text { interface components }\end{array}$ & & \\
\hline $\begin{array}{l}\text { 1.2.1 Prerecorded } \\
\text { Audio-only and } \\
\text { Video-only }[\mathrm{A}] \\
\end{array}$ & 1194.22(a) & $\begin{array}{l}\text { Provides that prerecorded } \\
\text { audio is available in a visible } \\
\text { format and that silent } \\
\text { animations are available in an } \\
\text { audible format }\end{array}$ & $\begin{array}{l}\text { Substantially } \\
\text { Equivalent }\end{array}$ & $\begin{array}{l}\text { Proposed standard provides } \\
\text { additional detail for } 8 \text { common } \\
\text { categories of non-text content. }\end{array}$ \\
\hline $\begin{array}{l}\text { 1.2.2 Captions } \\
\text { (Prerecorded) }[\mathrm{A}]\end{array}$ & $\begin{array}{l}1194.22(b) \text { and } \\
.24(c)\end{array}$ & $\begin{array}{l}\text { Provides for synchronized } \\
\text { captioning of prerecorded } \\
\text { video and multimedia. }\end{array}$ & & \\
\hline \begin{tabular}{|l|}
1.2 .3 Audio \\
Description or \\
Media Alternative \\
(Prerecorded) $[\mathrm{A}]$ \\
\end{tabular} & $\begin{array}{l}1194.22(b) \text { and } \\
.24(d)\end{array}$ & $\begin{array}{l}\text { Provides for audio description } \\
\text { of prerecorded video and } \\
\text { multimedia }\end{array}$ & & \\
\hline $\begin{array}{l}\text { 1.2.4 Captions } \\
\text { (Live) [AA] }\end{array}$ & $\begin{array}{l}1194.22(b) \text { and } \\
24(c)\end{array}$ & $\begin{array}{l}\text { Provides for captioning of live } \\
\text { video and multimedia }\end{array}$ & & \\
\hline $\begin{array}{l}1.2 .5 \text { Audio } \\
\text { Description } \\
\text { (Prerecorded) } \\
{[\mathrm{AA}]}\end{array}$ & $\begin{array}{l}1194.22(\mathrm{~b}) \text { and } \\
.24(\mathrm{~d})\end{array}$ & $\begin{array}{l}\text { Provides for audio description } \\
\text { of live video and multimedia }\end{array}$ & $\begin{array}{l}\text { Substantially } \\
\text { Equivalent }\end{array}$ & $\begin{array}{l}\text { Proposed standard distinguishes } \\
\text { between live and prerecorded media. }\end{array}$ \\
\hline $\begin{array}{l}\text { 1.3.1 Information } \\
\text { and Relationships } \\
\text { [A] }\end{array}$ & $\begin{array}{l}1194.22(\mathrm{e}) \\
\text { through (h) }\end{array}$ & $\begin{array}{l}\text { Provides that information, } \\
\text { structure, and relationships } \\
\text { conveyed visually are } \\
\text { available to users of assistive } \\
\text { technology } \\
\text { Provides that semantic } \\
\text { markup be used for headings, } \\
\text { lists, emphasized or special } \\
\text { text, and tabular data, } \\
\text { including the association of } \\
\text { data cells with their headers }\end{array}$ & $\begin{array}{l}\text { Substantially } \\
\text { Equivalent }\end{array}$ & $\begin{array}{l}\text { Proposed standard is written broadly } \\
\text { and is technology neutral, whereas } \\
\text { existing standard is specific to } \\
\text { HTML image maps and data tables. }\end{array}$ \\
\hline $\begin{array}{l}1.3 .2 \text { Meaningful } \\
\text { Sequence }[\mathrm{A}]\end{array}$ & None & $\begin{array}{l}\text { Provides for a reasonable and } \\
\text { logical reading order when } \\
\text { using assistive technology }\end{array}$ & New & \\
\hline
\end{tabular}




\begin{tabular}{|c|c|c|c|c|}
\hline \begin{tabular}{|c|} 
Proposed \\
(WCAG 2.0 \\
Success Criteria \\
[Level] $)$
\end{tabular} & \begin{tabular}{|c|} 
Existing 508 \\
Corresponding \\
Provision \\
\end{tabular} & Summary & $\begin{array}{c}\text { What would } \\
\text { Change }\end{array}$ & Comment \\
\hline $\begin{array}{l}1.3 .3 \text { Sensory } \\
\text { Characteristics } \\
{[\mathrm{A}]}\end{array}$ & None & $\begin{array}{l}\text { Provides that instructions are } \\
\text { not conveyed only through } \\
\text { sound, shape, size, or visual } \\
\text { orientation }\end{array}$ & New & \\
\hline $\begin{array}{l}\text { 1.4.1 Use of } \\
\text { Color }[\mathrm{A}]\end{array}$ & $\begin{array}{l}1194.21(\mathrm{i}) \text { and } \\
22(\mathrm{c})\end{array}$ & $\begin{array}{l}\text { Provides that information and } \\
\text { prompts are not conveyed } \\
\text { only through color }\end{array}$ & $\begin{array}{l}\text { Substantially } \\
\text { Equivalent }\end{array}$ & No technical difference. \\
\hline $\begin{array}{l}\text { 1.4.2 Audio } \\
\text { Control }[\mathrm{A}]\end{array}$ & None & $\begin{array}{l}\text { Provides that there is a way to } \\
\text { stop, pause, mute, or adjust } \\
\text { volume with audio that plays } \\
\text { automatically }\end{array}$ & New & \\
\hline $\mid \begin{array}{l}1.4 .3 \text { Contrast } \\
\text { (Minimum) }[\mathrm{AA}]\end{array}$ & None & $\begin{array}{l}\text { Provides for specified contrast } \\
\text { between foreground and } \\
\text { background of text and } \\
\text { images of text }\end{array}$ & New & \\
\hline $\begin{array}{l}\text { 1.4.4 Resize Text } \\
\text { [AA] }\end{array}$ & None & $\begin{array}{l}\text { Provides tor content that } \\
\text { remains readable and } \\
\text { functional when the font size } \\
\text { is doubled }\end{array}$ & New & \\
\hline $\begin{array}{l}\text { 1.4.5 Images of } \\
\text { Text [AA] }\end{array}$ & 1194.21(f) & $\begin{array}{l}\text { Provides for the use of text, as } \\
\text { opposed to images of text }\end{array}$ & \begin{tabular}{|l|} 
Substantially \\
Equivalent
\end{tabular} & $\begin{array}{l}\text { Proposed standard provides detail for } \\
\text { two situations where images of text } \\
\text { are permissible. }\end{array}$ \\
\hline $\begin{array}{l}\text { 2.1.1 Keyboard } \\
{[\mathrm{A}]}\end{array}$ & 1194.21(a) & $\begin{array}{l}\text { Provides for functionality } \\
\text { when using only the keyboard } \\
\text { interface }\end{array}$ & $\begin{array}{l}\text { Substantially } \\
\text { Equivalent }\end{array}$ & $\begin{array}{l}\text { Proposed standard clarifies the } \\
\text { requirement by emphasizing the } \\
\text { method of input, rather than the } \\
\text { nature of the output. }\end{array}$ \\
\hline $\begin{array}{l}2.1 .2 \text { No } \\
\text { Keyboard Trap } \\
\text { [A] }\end{array}$ & None & $\begin{array}{l}\text { Provides that the keyboard } \\
\text { focus is not trapped when the } \\
\text { keyboard is used for } \\
\text { navigation }\end{array}$ & New & \\
\hline $\begin{array}{l}\text { 2.2.1 Timing } \\
\text { Adjustable }[\mathrm{A}]\end{array}$ & 1194.22(p) & $\begin{array}{l}\text { Provides for flexible time } \\
\text { limits }\end{array}$ & $\begin{array}{l}\text { Substantially } \\
\text { Equivalent }\end{array}$ & $\begin{array}{l}\text { Proposed standard provides } \\
\text { additional options to the single } \\
\text { approach specified in the existing } \\
\text { provision (that the user "be alerted } \\
\text { and given sufficient time to indicate } \\
\text { more time is required"). }\end{array}$ \\
\hline $\begin{array}{l}\text { 2.2.2 Pause, Stop, } \\
\text { Hide [A] }\end{array}$ & 1194.21(h) & $\begin{array}{l}\text { Provides for user control over } \\
\text { moving, blinking, scrolling, } \\
\text { and information that updates } \\
\text { automatically }\end{array}$ & $\begin{array}{l}\text { Substantially } \\
\text { Equivalent }\end{array}$ & $\begin{array}{l}\text { Proposed standard specifies options } \\
\text { (pause, stop, hide, or control the } \\
\text { frequency) instead of "displayable in } \\
\text { at least one non-animated } \\
\text { presentation mode", and allows for } \\
\text { when animation "is part of an activity } \\
\text { where it is essential" (for example, } \\
\text { data that is being updated in real } \\
\text { time). }\end{array}$ \\
\hline $\begin{array}{l}\text { 2.3.1 Three } \\
\text { Flashes or Below } \\
\text { Threshold }[\mathrm{A}] \\
\end{array}$ & $\begin{array}{l}1194.21(\mathrm{k}) \text { and } \\
.22(\mathrm{j})\end{array}$ & $\begin{array}{l}\text { Provides that nothing flashes } \\
\text { more than three times per } \\
\text { second, unless the flash is } \\
\text { very small and does not } \\
\text { contain too much red }\end{array}$ & $\begin{array}{l}\text { Substantially } \\
\text { Equivalent }\end{array}$ & $\begin{array}{l}\text { Proposed standard takes into } \\
\text { consideration the size and hue of the } \\
\text { flash. }\end{array}$ \\
\hline $\begin{array}{l}\text { 2.4.1 Bypass } \\
\text { Blocks [A] }\end{array}$ & 1194.22(o) & $\begin{array}{l}\text { Provides for a skip navigation } \\
\text { link or other means to bypass } \\
\text { repetitive content }\end{array}$ & $\begin{array}{l}\text { Substantially } \\
\text { Equivalent }\end{array}$ & $\begin{array}{l}\text { Proposed standard uses the phrase } \\
\text { "blocks of content that are repeated" } \\
\text { instead of just "repetitive navigation } \\
\text { links". }\end{array}$ \\
\hline $\begin{array}{l}\text { 2.4.2 Page Title } \\
{[\mathrm{A}]}\end{array}$ & 1194.22(i) & $\begin{array}{l}\text { Provides for descriptive and } \\
\text { informative page titles }\end{array}$ & $\begin{array}{l}\text { Substantially } \\
\text { Equivalent }\end{array}$ & $\begin{array}{l}\text { Proposed standard is for all types of } \\
\text { content instead of just HTML frames. }\end{array}$ \\
\hline
\end{tabular}




\begin{tabular}{|c|c|c|c|c|}
\hline \begin{tabular}{|c|} 
Proposed \\
(WCAG 2.0 \\
Success Criteria \\
[Level] $)$ \\
\end{tabular} & \begin{tabular}{|c|} 
Existing 508 \\
Corresponding \\
Provision
\end{tabular} & Summary & $\begin{array}{c}\text { What would } \\
\text { Change }\end{array}$ & Comment \\
\hline $\begin{array}{l}\text { 2.4.3 Focus Order } \\
{[\mathrm{A}]}\end{array}$ & None & \begin{tabular}{|l|} 
Provides for a keyboard- \\
oriented navigation order that \\
is reasonable and logical \\
Provides that links, form \\
elements, and other user \\
interface controls and \\
components have a reasonable \\
and logical navigation order
\end{tabular} & New & \\
\hline \begin{tabular}{|l|}
2.4 .4 Link \\
Purpose (In \\
Context) $[\mathrm{A}]$ \\
\end{tabular} & None & $\begin{array}{l}\text { Provides that the purpose of } \\
\text { any link is understandable } \\
\text { from its text or context }\end{array}$ & New & \\
\hline $\begin{array}{l}\text { 2.4.5 Multiple } \\
\text { Ways [AA] }\end{array}$ & None & $\begin{array}{l}\text { Provides for two or more } \\
\text { means to locate content }\end{array}$ & New & \\
\hline $\begin{array}{l}\text { 2.4.6 Headings } \\
\text { and Labels [AA] }\end{array}$ & None & $\begin{array}{l}\text { Provides that headings and } \\
\text { labels are descriptive }\end{array}$ & New & \\
\hline $\begin{array}{l}\text { 2.4.7 Focus } \\
\text { Visible }[\mathrm{AA}]\end{array}$ & 1194.21(c) & $\begin{array}{l}\text { Provides that the keyboard } \\
\text { focus is visually apparent } \\
\text { when using the keyboard to } \\
\text { navigate }\end{array}$ & $\begin{array}{l}\text { Substantially } \\
\text { Equivalent }\end{array}$ & $\begin{array}{l}\text { Proposed standard uses the phrase } \\
\text { "indicator is visible" instead of } \\
\text { "well-defined on-screen indication". }\end{array}$ \\
\hline $\begin{array}{l}\text { 3.1.1 Language of } \\
\text { Page }[\mathrm{A}]\end{array}$ & None & $\begin{array}{l}\text { Provides that the default } \\
\text { language of content is } \\
\text { exposed to assistive } \\
\text { technology }\end{array}$ & New & \\
\hline $\begin{array}{l}\text { 3.1.2 Language of } \\
\text { Parts [AA] }\end{array}$ & None & $\begin{array}{l}\text { Provides that changes in } \\
\text { language are exposed to } \\
\text { assistive technology }\end{array}$ & New & \\
\hline $\begin{array}{l}3.2 .1 \text { On Focus } \\
{[\mathrm{A}]}\end{array}$ & $\begin{array}{l}1194.21(1) \text { and } \\
.22(\mathrm{n})\end{array}$ & $\begin{array}{l}\text { Provides that user interface } \\
\text { components do not initiate a } \\
\text { change of context when } \\
\text { receiving focus }\end{array}$ & & \multirow{2}{*}{$\begin{array}{l}\text { Proposed standard is explicit instead } \\
\text { of having the requirement implicit in } \\
\text { that "the form shall allow people } \\
\text { using assistive technology to access } \\
\text { the information, field elements, and } \\
\text { functionality required for completion } \\
\text { and submission of the form, } \\
\text { including all directions and cues." }\end{array}$} \\
\hline $\begin{array}{l}\text { 3.2.2 On Input } \\
{[\mathrm{A}]}\end{array}$ & $\begin{array}{l}1194.21(1) \text { and } \\
.22(\mathrm{n})\end{array}$ & $\begin{array}{l}\text { Provides that changing the } \\
\text { setting of user interface } \\
\text { components does not } \\
\text { automatically cause a change } \\
\text { of context }\end{array}$ & $\begin{array}{l}\text { Substantially } \\
\text { Equivalent }\end{array}$ & \\
\hline $\begin{array}{l}\text { 3.2.3 Consistent } \\
\text { Navigation [AA] }\end{array}$ & None & $\begin{array}{l}\text { Provides that repeated } \\
\text { navigational components } \\
\text { occur in the same relative } \\
\text { order each time they are } \\
\text { encountered }\end{array}$ & New & \\
\hline $\begin{array}{l}\text { 3.2.4 Consistent } \\
\text { Identification } \\
{[\mathrm{AA}]}\end{array}$ & 1194.21(e) & $\begin{array}{l}\text { Provides that components } \\
\text { having the same functionality } \\
\text { are identified consistently }\end{array}$ & $\begin{array}{l}\text { Substantially } \\
\text { Equivalent }\end{array}$ & $\begin{array}{l}\text { Proposed standard is for all types of } \\
\text { content instead of just "bitmap } \\
\text { images". }\end{array}$ \\
\hline $\begin{array}{l}\text { 3.3.1 Error } \\
\text { Identification }[\mathrm{A}]\end{array}$ & $\begin{array}{l}1194.21(1) \text { and } \\
22(\mathrm{n})\end{array}$ & $\begin{array}{l}\text { Provides that automatically } \\
\text { detected input errors are } \\
\text { identified and described in } \\
\text { text to the user }\end{array}$ & 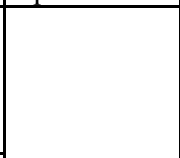 & \multirow{2}{*}{$\begin{array}{l}\text { Proposed standard is explicit instead } \\
\text { of having the requirement implicit in } \\
\text { that "the form shall allow people } \\
\text { using assistive technology to access } \\
\text { the information, field elements, and } \\
\text { functionality required for completion } \\
\text { and submission of the form, } \\
\text { including all directions and cues." }\end{array}$} \\
\hline $\begin{array}{l}\text { 3.3.2 Labels or } \\
\text { Instructions [A] }\end{array}$ & $\begin{array}{l}1194.21(1) \text { and } \\
.22(\mathrm{n})\end{array}$ & $\begin{array}{l}\text { Provides for labels or } \\
\text { instructions when content } \\
\text { requires user input }\end{array}$ & $\begin{array}{l}\text { Substantially } \\
\text { Equivalent }\end{array}$ & \\
\hline $\begin{array}{l}\text { 3.3.3 Error } \\
\text { Suggestion }[\mathrm{AA}]\end{array}$ & None & $\begin{array}{l}\text { Provides that the system } \\
\text { makes suggestions for } \\
\text { correction when input errors } \\
\text { are automatically detected and } \\
\text { suggestions are available }\end{array}$ & New & \\
\hline
\end{tabular}




\begin{tabular}{|c|c|c|c|c|}
\hline \begin{tabular}{|c|} 
Proposed \\
(WCAG 2.0 \\
Success Criteria \\
{$[$ Level] $)$} \\
\end{tabular} & \begin{tabular}{|c|} 
Existing 508 \\
Corresponding \\
Provision
\end{tabular} & Summary & $\begin{array}{c}\text { What would } \\
\text { Change }\end{array}$ & Comment \\
\hline $\begin{array}{l}\text { 3.3.4 Error } \\
\text { Prevention } \\
\text { (Legal, Financial, } \\
\text { Data) }[\mathrm{AA}]\end{array}$ & None & $\begin{array}{l}\text { Provides that when legal, } \\
\text { financial, or test data can be } \\
\text { changed or deleted the } \\
\text { changes or deletions can be } \\
\text { reversed, verified, or } \\
\text { confirmed }\end{array}$ & New & \\
\hline 4.1.1 Parsing [A] & None & $\begin{array}{l}\text { Provides that significant } \\
\text { HTML/XHTML validation } \\
\text { and parsing errors in source } \\
\text { code are avoided }\end{array}$ & New & \\
\hline $\begin{array}{l}\text { 4.1.2 Name, Role, } \\
\text { Value [A] }\end{array}$ & $1194.21(d)$ & $\begin{array}{l}\text { Provides that sufficient } \\
\text { information (including } \\
\text { identity, operation, and state) } \\
\text { about user interface } \\
\text { components is available to } \\
\text { assistive technology }\end{array}$ & $\begin{array}{l}\text { Substantially } \\
\text { Equivalent }\end{array}$ & $\begin{array}{l}\text { Proposed standard uses the phrase } \\
\text { "programmatically determined" } \\
\text { instead of "available to assistive } \\
\text { technology". }\end{array}$ \\
\hline
\end{tabular}

Source: https://www.access-board.gov/guidelines-and-standards/communications-andit/about-the-ict-refresh/background/comparison-table-of-wcag2-to-existing-508-standards

\section{Appendix E - Thompson et al. Accessibility Ratings by Presence of}

\section{Accessibility policy.}

From (Thompson T. C., 2013)

Research Question 4: Which independent variables are the best predictors of web and PDF accessibility?

Overall, the webpages on the websites of institutions with an accessibility policy of any type had higher overall accessibility ratings. Figure 1 shows the prevalence of various accessibility features across the institutions, with nearly $80 \%$ overall including HTML headings, down to about $3 \%$ including ARIA landmarks. The specific features where having a policy may make a difference are: the inclusion of alt text with images; labeled input fields; and especially, having an accessibility link 
on the home page. Having a policy is negatively associated with having tagged PDF. Once again, these effect sizes are small, due to the large amount of variance within the two groups.

Figure 1. Accessibility ratings by presence of accessibility policy

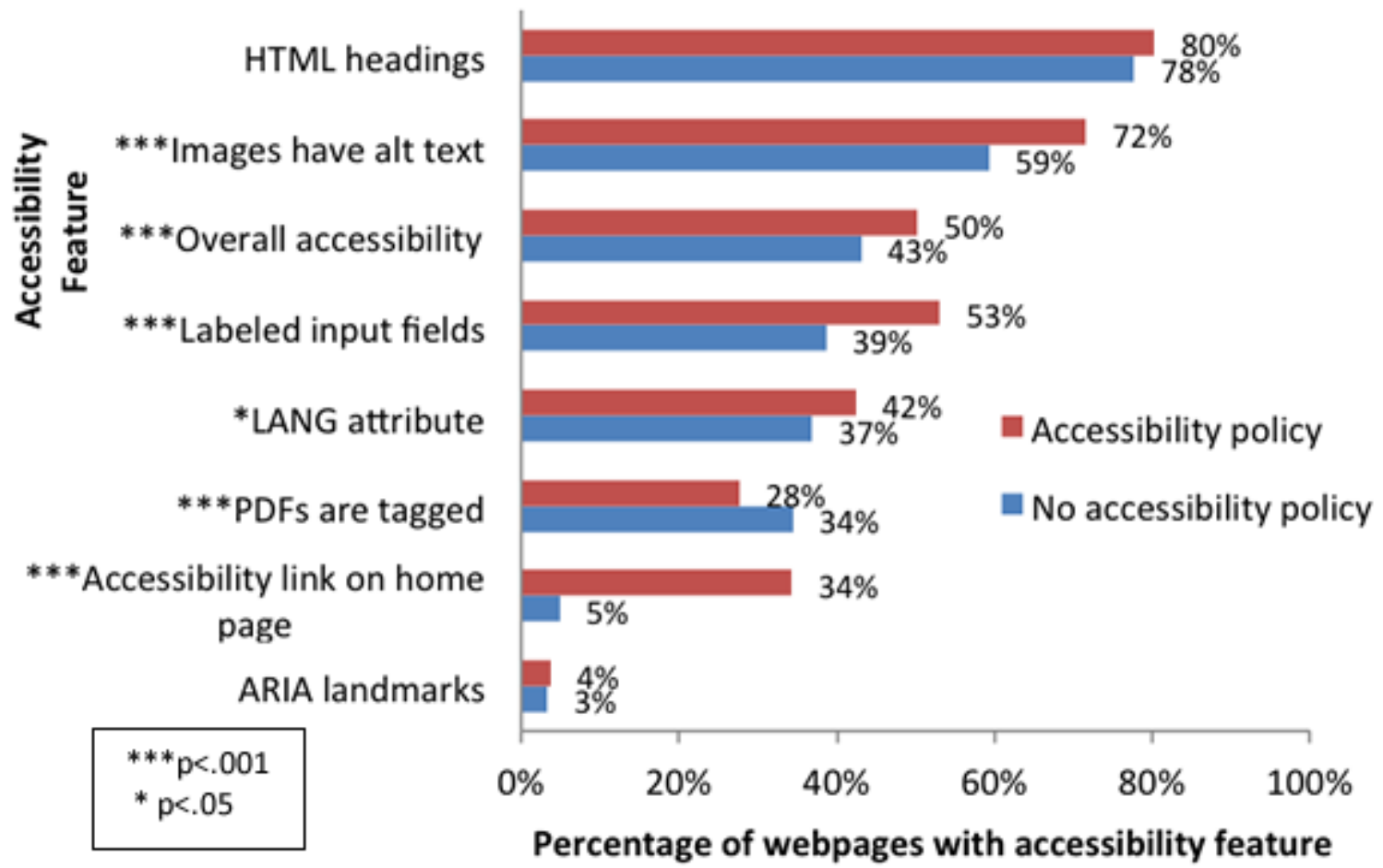

Figure 2 shows the relationship between an accessibility policy and the level of conversation about web and/or technology accessibility. When the institution's home page has an accessibility link, the overall level of conversation is much higher than at institutions without an accessibility link on the home page, and higher yet among institutions that also have an accessibility policy. Among institutions without an accessibility link on the home page, institutions with an accessibility policy average nearly 10 times the level of conversation as those without an accessibility policy. 


\section{Appendix F - Sample of Ontario Websites}

\begin{tabular}{|c|c|c|}
\hline Category & Total & Organizations \\
\hline $\begin{array}{l}\text { Colleges and } \\
\text { Universities }\end{array}$ & 6 & 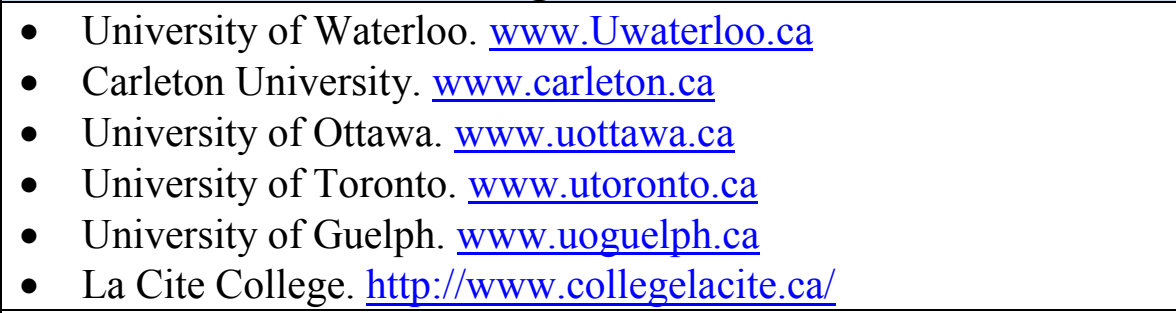 \\
\hline $\begin{array}{l}\text { Non-Profit } \\
\text { Organizations }\end{array}$ & 4 & $\begin{array}{l}\text { - } \quad \text { Toronto District School Board. www.tdsb.on.ca } \\
\text { - } \quad \text { Peel District School Board. www.peelschools.org } \\
\text { - } \text { Hamilton Health Sciences Corporation. } \\
\text { www.hamiltonhealthsciences.ca } \\
\text { Cancer Care Ontario. www.cancercare.on.ca }\end{array}$ \\
\hline $\begin{array}{l}\text { State and local } \\
\text { Government } \\
\text { Organizations } \\
\text {-became- } \\
\text { Municipal, } \\
\text { Provincial, } \\
\text { Federal } \\
\text { Organizations }\end{array}$ & 7 & $\begin{array}{ll}\text { - } & \text { Canada Post Corporation. www.canadapost.ca } \\
\text { - } & \text { Burke's Falls Public Library. www.burksfallslibrary.com } \\
\text { - } & \text { Toronto Public Library. http://www.torontopubliclibrary.ca/ } \\
\text { - } & \text { Ontario Power Generation. } \underline{\text { www.opg.com }} \\
\text { - } & \text { City of Ottawa. www.ottawa.ca } \\
\text { - } & \text { Ontario Government. www.ontario.ca } \\
\text { - } & \text { Federal Government of Canada. } \\
& \text { https://www.canada.ca/en.html } \\
\end{array}$ \\
\hline $\begin{array}{l}\text { Information } \\
\text { Technology } \\
\text { Firms }\end{array}$ & 5 & $\begin{array}{l}\text { - The Woodbridge Company Limited (Thomson Reuter } \\
\text { Corporation.) www.thomsonreuters.com } \\
\text { - } \text { Rogers Communications. www.rogers.com } \\
\text { - Canadian Broadcasting Corporation. www.cbc.radio-canada.ca } \\
\text { - IBM Canada LTD. www.ibm.ca } \\
\text { - } \text { Bell Media. www.bellmedia.ca }\end{array}$ \\
\hline $\begin{array}{l}\text { Manufacturing } \\
\text { Firms }\end{array}$ & 5 & $\begin{array}{l}\text { - } \quad \text { Magna International Inc. www.magna.com } \\
\text { - } \text { Ontario Solar Provider Group } \\
\text { - } \text { https://solarprovidergroup.com/ } \\
\text { - } \text { THREE0FOUR. } \text { http://www.conovey.com/ Motors of Canada Limited. www.gmcanada.com } \\
\text { - }\end{array}$ \\
\hline Private Firms & 7 & 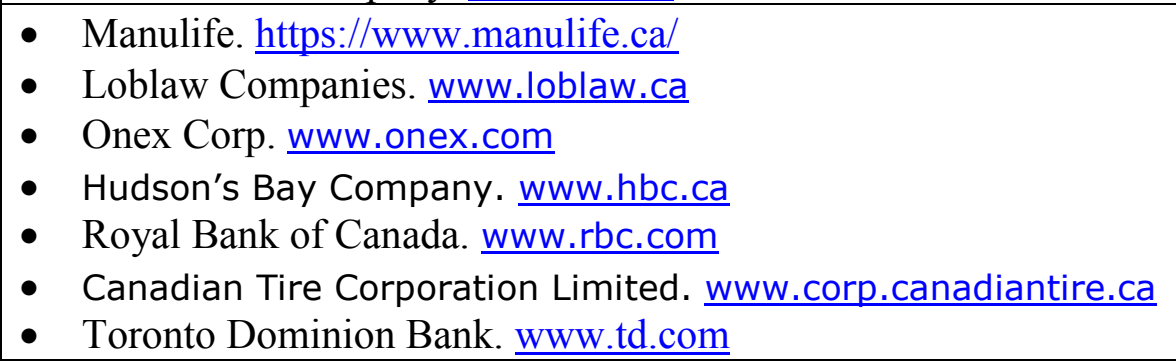 \\
\hline
\end{tabular}




\begin{tabular}{|c|c|c|}
\hline $\begin{array}{l}\text { Sports and } \\
\text { Recreation }\end{array}$ & 2 & $\begin{array}{l}\text { - Maple Leafs Sports and Entertainment. www.mlse.com } \\
\text { - Ottawa Senators. } h \text { https://www.nhl.com/senators }\end{array}$ \\
\hline $\begin{array}{l}\text { Web } \\
\text { Development/ } \\
\text { Web Design } \\
\text { Firms }\end{array}$ & 4 & $\begin{array}{l}\text { - VJG Interactive. https://www.vjginteractive.com/ } \\
\text { - } \text { My Planet. www.myplanet.com } \\
\text { - } \\
\text { Arts and Scia. www.kinexmedia.com } \\
\text { https://artscience.ca/ }\end{array}$ \\
\hline $\begin{array}{l}\text { Health/ } \\
\text { Disability } \\
\text { Organizations }\end{array}$ & 6 & $\begin{array}{l}\text { - } \text { Extendicare Inc. www.extendicare.com } \\
\text { - } \text { Retirement Residences Real Estate Investment Trust. } \\
\text { www.reveraliving.com } \\
\text { - } \text { The Ottawa Hospital. www.ottawahospital.on.ca } \\
\text { - } \text { Accessibility for Ontarians with Disabilities Act. www.aoda.ca } \\
\text { - } \underline{\text { http://www.health.gov.on.ca/en/ }} \\
\text { - Centre for Addiction and Mental Health. } \\
\text { http://www.camh.ca/en/hospital/Pages/home.aspx }\end{array}$ \\
\hline $\begin{array}{l}\text { Software } \\
\text { Development } \\
\text { Firms }\end{array}$ & 4 & $\begin{array}{l}\text { - } \text { Ceriedian Canada Ltd. https://www.ceridian.ca/ } \\
\text { - } \quad \text { Digital Echidna. } \underline{\mathrm{https}: / / \mathrm{www} . \text { echidna.ca/ }} \\
\text { - } \quad \text { Intelliware Software Development. http://www.intelliware.com/ }\end{array}$ \\
\hline Total: & 50 & \\
\hline
\end{tabular}

Sources:

1. The Globe and Mail http://www.globeinvestor.com/series/top1000/tables/employers/2003/\#chewy

2. Top Web Design Companies in Canada: https://clutch.co/ca/web-designers

3. Top Software Development Companies in Canada: https://www.topseos.com/ca/best-web-development-companies-in-canada

4. Top universities and colleges in Ontario: http://www.macleans.ca/education/unirankings/university-rankings-2017comprehensive/

5. Largest non-profits in Canada: https://beta.theglobeandmail.com/report-onbusiness/rob-magazine/top-100-non-profit-organizations-registeredcharities/article17298702/?ref=http://www.theglobeandmail.com\&

6. Top Health/Disability Organizations: http://www.archdisabilitylaw.ca/usefullinks/disability-organizations 


\section{Bibliography}

Accessibility for Ontarians with Disabilities Act. (2005). Ontario Laws and Statutes.

Government of Ontario. Retrieved January 2018, from

https://www.ontario.ca/laws/statute/05a11

Amazon Alexa. (2017). Most Visited Websites. Retrieved from

https://www.alexa.com/topsites/countries/CA

Brajnik, G. Y. (2010). Testability and validity of WCAG 2.0: the expertise effect. . In:

ASSETS'10-Proceedings of the 12th International ACM SIGACCESS

Conference on Computers and Accessibility. Retrieved from

https://users.dimi.uniud.it/ giorgio.brajnik/papers/wcag-assets-2010.pdf

Brajnik, G. Y. (2010). Testability and validity of WCAG 2.0: the expertise effect. . ASSETS'10 - Proceedings of the 12th International ACM SIGACCESS Conference on Computers and Accessibility. Retrieved from https://users.dimi.uniud.it/ giorgio.brajnik/papers/wcag-assets-2010.pdf

Canada, J. V. (2012). Supreme Court of Canada. Retrieved from https://www.canlii.org/en/ca/fct/doc/2010/2010fc1197/2010fc1197.html

Canadian Broadcasting Corporation. (2013). Most Visited Websites By Country. Retrieved from http://www.cbc.ca/strombo/news/the-most-visited-websites-bycountry

Commission, D. R. (2004). The Web Access and Inclusion for Disabled People A Formal Investigation. Retrieved from https://disability-studies.leeds.ac.uk/wpcontent/uploads/sites/40/library/DRC-Web-FI.pdf 
Disability Rights Commission. . (2004). The Web Access and Inclusion for Disabled People A Formal Investigation. . Retrieved from https://disabilitystudies.leeds.ac.uk/wp-content/uploads/sites/40/library/DRC-Web-FI.pdf Ellcessor, E. (2014). Web Accessibility Myths as Negotiated Industry Lore. . Critical Studies in Media Communication. Volume 31, 2014 - 5. .

E-Soft, Inc.,. (2004). Technology Penetration Report. Retrieved from SecuritySpace.com European Union. (2012). Digital Single Market Policy on Website Accessibility. Retrieved from https://ec.europa.eu/digital-single-market/en/web-accessibility Fox, S. (2011). Americans living with disability and their technology profile. Washington: Pew Internet \& American Life Project. Retrieved from http://www.pewinternet.org/Reports/2011/Disability.aspx

Freire, A. R. (2008). A survey on the accessibility awareness of people involved in web development projects in Brazil. In Proceedings of the 2008 international crossdisciplinary conference on Web accessibility (W4A). In Proceedings of the 2008 international cross-disciplinary conference on Web accessibility (W4A), Beijing, China, ACM, New York, NY, USA, 87-96. .

Gibson, B. a. (2005). DHTML Accessibility - Solving the JavaScript Accessibility Problem. CSUN Technologies and Persons with Disabilities Conference. Retrieved from http://www.csun.edu/cod/conf/2005/proceedings/25 Gilbertson, T. M. (2012). Guidelines, icons and marketable skills: an accessibility evaluation of 100 web development company homepages. . Proceedings of the International Cross-Disciplinary Conference on Web Accessibility. . Retrieved from https://dl-acm- 
org.proxy.library.carleton.ca/citation.cfm?id=2207024\&CFID $=1011168649 \& \mathrm{CF}$ TOKEN $=41575398$

Ian M. Hull, J. A. (2004). Will Drafting Mistakes. . Retrieved from http://www.hullandhull.com/Text-From-2004-Breakfast-SeriesPresentations/june-2004.pd

Lazar, J. a. (2006). One year older, but not necessarily wiser: an evaluation of homepage accessibility problems over time. Univers.Access Inf.Soc. 4, 285-291.

Lazar, J. B.-D. (2003). Web accessibility in the Mid-Atlantic United States: a study of 50 homepages. 2: 331-341 DOI 10.1007 .

Lazar, J. D.-S. (2004). Improving web accessibility: a study of webmaster perceptions. Computers in Human Behavior 20, . doi:269-288

Lewthwaite, S. (2011). Critical approaches to accessibility for technology-enhanced learning,. Learning, Media and Technology, 36:1, 85-89, . doi:10.1080/17439884.2010.529915

Lopes, R. V. (2010). Redefining assumptions: accessibility and its stakeholders. In Proceedings of the 12th international conference on Computers helping people with special needs: Part I, Vienna, Austria, Springer-Verlag, Berlin, Heidelberg. doi:561-568

MacDonald, D. (2017). Telephone conversation with MacDonald, D. on November 18, 2017. 
Macdonald, D. (November 18, 2017. 3:30 - 4:00 pm). Conversation with David MacDonald, Professional Website Accessibility Consultant. Retrieved from http://www.davidmacd.com/index.html\#home

Mossa., T. H. (2015). ODSP: More Barriers than Opportunities. Retrieved from http://www.cilt.ca/Documents\%20of\%20the\%20CILT\%20Website/ODSP.pdf

Olalere, A. a. (2011). Accessibility of U.S. federal government home pages: Section 508 compliance and site accessibility statements. . Government Information Quarterly 28, 303-309.

Parmanto, B. (2010). Web Accessibility: A Foundation for Research. Journal of the American Society for Information Science and Technology. doi:10.1002/asi.21209

Program, G. G.-w. (Accessed July 2017). Section 508 Guidelines. Retrieved from https://www.section508.gov/

Ried, R. (2010). Javascript User Breakdown. Retrieved from http://blog.strictlysoftware.com/2009/09/javascript-usage-browser-breakdown.html

Rosenau, N. (2010). Precarious Pathways: Use of Residential Congregate Care by Children with Developmental Disabilities. . Retrieved from https://everychildtexas.org/wp-content/uploads/2017/08/Precarious-PathwaysLiterature-Review-CC-2010.pdf

Sauer, J. S. (2017). Implementing Recommendations From Web Accessibility Guidelines: A Comparative Study of Nondisabled Users and Users With Visual Impairments. . Human Factors. doi:10.1177/0018720817708397 
Seale, J. (2006). E-learning and disability in higher education: Accessibility research and practice. . Abingdon: Routledge . Retrieved from https://www.routledge.com/products/9780415629416

Slatin, J. R. (2003). Maximum Accessibility: Making Your Web Site More Usable for Everyone. Addison-Wesley,. Retrieved from https://dl.acm.org/citation.cfm?id=560695\&preflayout=flat

Statistics Canada. (2011). Your 2011 Census . Retrieved from https://www12.statcan.gc.ca/census-recensement/2011/dp-pd/index-eng.cfm Sullican, T. a. (2000). Barriers to use: usability and content accessiblity on the web's most popular sites. . Proceeding of the 2000 ACM conference on universal usability .

Sven Schmutz, A. S. (2017). Implementing Recommendations From Web Accessibility Guidelines: A Comparative Study of Nondisabled Users and Users With Visual Impairments. . Human Factors Vol 59, Issue 6, pp. 956 - 972. .

Termens, M. R. (2009). Web Content Accessibility Guidelines: from 1.0 to 2.0. Poster Sessions. Retrieved from https://www.researchgate.net/profile/Mireia_Ribera_Turro/publication/22102314 2_Web_content_accessibility_guidelines_from_10_to_20/links/02e7e 521f2c7711 fed000000/Web-content-accessibility-guidelines-from-10-to20.pdf?origin=publication_detail

Thompson, T. (2009). A Longitudinal Study on Higher Education Web Accessibility: Implications for Advocates. Boulder, Colorado,: In 12th Annual Accessing Higher Ground Accessible Media, Web and Technology Conference,. 
Thompson, T. B. (2003). Research On Web Accessibility In Higher Education. . Information Technology and Disabilities Journal. Volume IX Number 2, . Retrieved from http://itd.athenpro.org/volume9/number2/thompson.html Thompson, T. C. (2013). Seeking Predictors of Web Accessibility in U.S. Higher Education Institutions. Information Technology and Disabilities Journal. Volume XIII Number 1. Retrieved from http://itd.athenpro.org/volume13/number1/thompson.html

Toronto Public Library. (Accessed 2017). Accessibility. Retrieved from https://www.torontopubliclibrary.ca/accessibility/

United Nations. (2006). Convention on the Rights of Persons with Disabilities. Retrieved from http://www.un.org/disabilities/default.asp?id=61

United States Access Board. (2018). Comparison Table of WCAG 2.0 to Existing 508 Standards. . Retrieved from https://www.access-board.gov/guidelines-andstandards/communications-and-it/about-the-ict-refresh/background/comparisontable-of-wcag2-to-existing-508-standards

University of Toronto. (2012). A-prompt Web Accessibility Resource. . Retrieved from http://aprompt.snow.utoronto.ca/.

University of Towson. (2017). Biography of Professor Jonathan Lazar. Retrieved from http://orion.towson.edu/ jlazar/

Velleman, E. N. (2015). Factors explaining adoption and implementation processes for web accessibility standards within eGovernment systems and organizations. 
Universal Access in the Information Society.

doi:http://dx.doi.org/10.1007/s10209-015-0449-5

Vigo, M. A. (2007). Quantitative metrics for measuring web accessibility. In Proceedings of the 2007 international cross-disciplinary conference on Web accessibility (W4A) (W4A '07). ACM, New York, NY, USA, 99-107. Retrieved from http://dx.doi.org/10.1145/1243441.1243465

W3C Web Accessibility Initiative. (2005). Web Content Accessibility Guidelines Overview. Retrieved from https://www.w3.org/WAI/standards-guidelines/wcag/

WebAIM. (2010). Javascript as an Accessibility Concern. Retrieved from https://webaim.org/blog/javascript-as-an-accessibility-concern/

World Health Organization. (2016). Disability and Health. Retrieved from http://www.who.int/mediacentre/factsheets/fs352/en/

(2016). World Health Organization. Disability and Health. Retrieved from http://www.who.int/mediacentre/factsheets/fs352/en/

World Wide Web Consortium. (Accessed September 2017). Accessibility FAQs. Retrieved from https://www.w3.org/WAI/WCAG20/wcag2faq\#mobile

Yang, J. (2006). EU and US Javascript Disabled Index. Retrieved from http://visualrevenue.com/blog/2007/08/eu-and-us-javascript-disabled-index.html

Yue, C. W. (2009). Characterizing insecure javascript practices on the web. Proceedings of the 18th international conference on World wide web. doi:10.1145/1526709.1526838

Zeng, X. P. (2005). Metric for Web Accessibility Evaluation. . JOURNAL OF THE AMERICAN SOCIETY FOR INFORMATION SCIENCE AND 
TECHNOLOGY, 56(13):1394-1404 . Retrieved from

https://pdfs.semanticscholar.org/cd64/b51611e3547ed32091726b29101c9bf80bb7

.pdf 